\title{
Will Urban Migrants Formally Insure their Rural Relatives? Family Networks and Rainfall Index Insurance in Burkina Faso*
}

\author{
Harounan Kazianga ${ }^{\dagger}$ and Zaki Wahhaj ${ }^{\ddagger}$ \\ Oklahoma State University and University of Kent
}

November 2019

\begin{abstract}
Large segments of the population in developing countries, especially in rural areas, have a high level of vulnerability to weather-related shocks but have limited means to insure themselves against them. In recent years, microfinance institutions have experimented with microinsurance products, including rainfall index insurance, but the uptake of these products has generally been very low. We present findings from a pilot study exploring whether and how existing ties between urban migrants and rural farmers may be used to provide the latter improved access to formal insurance. Urban migrants in Ouagadougou (the capital of Burkina Faso) originating from nearby villages were offered, at the prevailing market price, a rainfall index insurance product that can potentially protect their rural relatives from adverse weather shocks. The product had an uptake of $22 \%$ during the two-week subscription window. Half the urban migrants in the study were randomly offered an insurance policy in which payouts would be made, not to the subscriber, but directly to the intended beneficiary. This feature increased uptake rates by 17-22 percentage points. We argue that rainfall index insurance can complement informal risk-sharing networks by mitigating problems of informational asymmetry and self-control issues.
\end{abstract}

Keywords: Microinsurance markets, Indexed insurance, Rainfall, Migration, Informal insurance networks

JEL Codes: O15, O16, G21

${ }^{*}$ The field work reported in this paper was made possible by a grant from the International Initiative for Impact Evaluation (titled TW13.1028: Enhancing access to weather index agricultural insurance in Burkina Faso - A new marketing approach) with support from Oklahoma State University and the University of Kent and the collaboration of PlaNet Guarantee. Alassane Koulibaly, Arthur Sagot-Duvauroux and Oumar Sory from The Innovation for Poverty Action (IPA) provided exceptional administrative and research assistance throughout the project. Harounan Kazianga acknowledges also support from the Carson Priority Endowed Professorship.

$\dagger$ Email: harounan.kazianga@okstate.edu. Address: 324 Business Building, Spears School of Business, Oklahoma State University, Stillwater, OK 74078, USA

${ }_{\ddagger}^{\ddagger}$ Email: z.wahhaj@kent.ac.uk. Address: School of Economics, Keynes College, University of Kent, Canterbury CT2 7NP, United Kingdom. 


\section{Introduction}

It is a well-documented fact that large segments of the population in developing countries, especially in rural areas, have a high level of vulnerability to weather-related shocks (Binswanger and Rosenzweig, 1993, Townsend, 1994, Dercon, 2002). Agricultural households adopt a range of risk-coping strategies to cope with these shocks, including income-smoothing and self-insurance. But these strategies can involve significant sacrifices in terms of foregone profits and long-term productivity (Morduch, 1995; Dercon, 2002). While there is evidence of informal risk-sharing among rural households (Scott, 1977, Townsend, 1994; Udry, 1994; Ligon et al., 2002; Fafchamps and Lund, 2003), these mechanisms are unlikely to be effective when the risk-sharing network experiences covariate shocks. On the other hand, there is limited usage of formal insurance products among these populations. A study by the International Labor Organization estimated that, in Africa alone, there are approximately 700 million working poor and vulnerably non-poor on the continent, with an annual income of 500 billion USD, who can potentially benefit from formal insurance (Matul et al. 2010). Less than $3 \%$ of this population currently use insurance products.

In recent years, microfinance institutions have experimented with insurance products, in particular rainfall index insurance, in different parts of the world. But the uptake of these products has generally been very low (Cole et al. 2013). It is evident that there is a mismatch between the type of formal insurance products that microfinance institutions are currently providing and the demand of poor rural farmers. The existing literature points to a number of explanations for this phenomenon including the high opportunity cost of insurance premiums for poor farmers (Giné et al., 2008, Gaurav et al., 2011), their reliance on informal risk-sharing networks (Mobarak and Rosenzweig, 2013, 2012, Binswanger-Mkhize, 2012), lack of familiarity with the concept of insurance (Platteau, 1997), as well as lack of trust in the insurance provider and liquidity constraints (Cole et al., 2013). Recent research on the topic has argued that formal insurance can complement exist-

ing informal risk-sharing arrangements by providing informal insurance groups protection against aggregate shocks (Dercon et al., 2014, Mobarak and Rosenzweig, 2013, 2012, Berg et al., 2009).

In this paper, we present findings from a pilot study exploring how existing ties between urban migrants and rural farmers can be used to provide the latter improved access to formal insurance. The study is motivated by well-established evidence regarding the use of rural-urban migration as a risk-coping and risk-management strategy (e.g. Lucas, 1997, Rosenzweig and Stark, 1989, Stark and Lucas, 1988) and that rural households in developing countries often rely upon assistance from close relatives among urban migrants to cope with adverse weather-related shocks (e.g. Rosenzweig and Stark, 1989, Kazianga, 2006, Yang and Choi, 2007, Dustmann et al., 2017). Our central hypothesis is that demand for weather index insurance can be increased by offering the product to urban migrants, as a mean of providing coverage for their rural relatives engaged in farming. The advantage of marketing the product to urban migrants is that they are easier to access for the 
insurance provider, thus lowering transaction costs; they are likely to have more experience with formal financial products; and they are likely to be less financially constrained when required to pay for the policy.

To test this hypothesis, we collected contact information on all individuals who had migrated to urban areas from a random sample of rural households from villages close to Ouagadougou, the capital city in Burkina Faso. The urban migrants were traced, and invited to attend a demonstration of an existing rainfall index insurance product designed for small-scale rural farmers in Burkina Faso (by the organisation PlaNet Guarantee). Subsequently, all the urban migrants in the study were contacted and offered subscription to an insurance policy (at the existing market price) for agricultural plots farmed by their rural relatives, with the contract specifying indemnity payments to be paid either to the subscriber or directly to the farmer. The main, descriptive, finding from the study is that this exercise generated an uptake rate of $22 \%$ among the urban migrants over the two-week period of the trial. The cost per subscription during the urban pilot was $38-50 \%$ lower than the corresponding cost in Planet Guarantee's existing system for marketing weather index insurance in rural Burkina Faso, which suggests that marketing formal insurance to rural farmers via urban migrants can potentially improve its cost-effectiveness.

The study involved the randomisation of one feature of the insurance policy. Specifically, half the urban migrants in the study were offered an insurance policy in which payouts would be made directly to the rural farmer on whose behalf the insurance was purchased. The other half were offered a policy where payouts would be made to the subscriber. The uptake rate was higher (by 17-22 percentage points) among the first group. In the focus group discussions conducted prior to the marketing phase, urban migrants explained that they preferred this option because of the possible temptation to use an insurance payout, intended for their rural relative, for some other purpose (Banerjee and Mullainathan, 2010). We also find, based on descriptive analysis, that the uptake was higher among urban migrants who reported at least one shock covered by the policy suffered by their rural relative in the preceding 5 years. However, the shock reports of the urban migrants and the rural relatives do not correspond (Batista and Narciso, 2016, Seshan and Zubrickas, 2017) - pointing to informational asymmetry within the informal risk-sharing network - and the uptake rates do not respond to shocks reported by the latter.

Our findings have a number of important implications for understanding the potential of formal index-based insurance in developing countries. First, we demonstrate that it is feasible to market rainfall index insurance via urban migrants. Thus, the market is not limited to those who are directly engaged in rural farming; given the importance of rural-urban migrant links for coping with risk in developing countries, the potential client base is substantially larger. The randomised component of the intervention demonstrates that insurance uptake by urban migrants can be improved by specifying insurance payouts directly to the rural beneficiary. Additionally, the descriptive patterns in the data suggest that rainfall index insurance can complement informal risk-sharing networks by 
mitigating problems of informational asymmetry as insurance payments are contingent on objective reports of shocks.

While we were not able to test the following hypothesis, we also surmise that marketing rainfall index insurance via urban migrants can (i) improve understanding of such products among their rural relatives covered under the policy, and eventually increase uptake among rural farmers themselves; (ii) reduce the need for urban migrants to maintain liquidity to assist their rural relatives in the event of adverse weather shocks, and thus enable them to pursue more profitable economic opportunities.

\section{Study Context and Intervention}

The study was conducted with small-holder farmers in rural Burkina Faso and migrants from these households presently living in Ouagadougou. The majority of farmers are engaged in rainfed subsistence agriculture. The rainfall occurs during a single wet season lasting three to five months (May to September) and is highly variable. Consequently, the majority of rural households are exposed to weather-related risks and rely primarily on informal insurance mechanisms (Kazianga and Udry, 2006). According to data from the Burkinabe Ministry of Agriculture survey of 2015, nearly $78 \%$ of households cope with adverse shocks through consumption of own stocks. By contrast, less than $2 \%$ rely on formal insurance.

The wider context for the study is that there are approximately 700 million working poor and vulnerable non-poor in Africa, who can potentially benefit from formal insurance. However, less than $3 \%$ of this population currently uses micro-insurance products (Matul et al., 2010). As of 2016, there were 16 insurance companies registered with the Burkinabe Ministry of Finance including PlaNet Guarantee. A specific regulatory framework for micro-insurance was introduced in 2011 by CIMA (Conférence InterAfricaine des Marchés de l'Assurance), which groups 14 countries, including Burkina Faso, under the same regional regulation and control mechanism.

In our study area (discussed in more detail in the following sections) more than half the rural households have at least one relative living in Ouagadougou and more than two-thirds of them report receiving transfers from their Ouagadougou-based relative. The literature on rural-urban linkages in West Africa, including Burkina Faso, points to a slowdown of urban growth since the 1990s and a new phenomenon of 'reverse migration' from urban to rural areas in response to financial insecurity and the high cost of living in urban areas (Beauchemin, 2011; Potts, 2008). More generally, "migrants still maintain close relations with their birth village even from a distance; they return to visit; they invest in housing, social activities, education, and health amenities ... Traditionally, the birth village is the preferred place for eventual retirement ... Most first try to find a new job in cities or towns [but] ... If they fail (as many do) the village is their last resort" Beauchemin and Bocquier, 2004). Thus, for urban migrants, the possibility of eventual 
return as a social safety net serves as a strong incentive to invest in their existing social ties in rural areas, including providing financial support to their rural relatives in times of need.

The intervention was based on PlaNet Guarantee's existing rainfall index insurance product designed for small-scale rural farmers in Burkina Faso. Subscribers can insure themselves against rainfall shortages in a specified location within the organisation's coverage area. Rainfall is measured using satellite data at a resolution of 10 square kilometers, and payouts are a function of rainfall realisation over a period of 100 days, with distinction made between three stages of plant growth (germination, second-stage growth, fruit and flowering). Planet Guarantee's current subscription rate in rural areas is between 20 and $35 \%$ with marketing costs between 20,000 FCFA 11 and 40,000 FCFA per subscription. The insurance premium varied, depending on the region, between $7.75 \%$ and $11.5 \%$ of the amount insured. The intervention involved marketing the product to urban migrants in Ouagadougou who originate from villages and have relatives engaged in farming. More precisely, urban migrants were given the opportunity to purchase insurance for agricultural plots farmed by their rural relatives, with the contract specifying indemnity payments to be paid either to the subscriber or directly to their rural relative. This feature of the contract was randomised across the urban migrants, with half being offered a contract in which payments would be made to the subscriber and half being offered a contract in which payments would be made to the rural relative. The policy was offered to the urban migrants at the market price, i.e. Planet Guarantee's standard price for the insurance policy as offered to rural farmers.

\section{Description of the Study Sample and Surveys}

The study required both a sample of rural farmers and a sample of urban migrants with family ties in rural areas. Furthermore, to meet the broader objectives of the study, we needed an urban migrant sample with village-based extended family members representative of the rural population - at least for some regions of Burkina Faso.

To construct the sample, we began by randomly selecting 20 villages from the Plateau Central and Centre Ouest regions of Burkina Faso. These two regions were chosen for their proximity to Ouagadougou. At the time of the study, the implementing agency Planet Guarantee was active in one of the regions but not in the other. We randomly selected 10 villages in each region from a restricted set of villages meeting the following criteria: (i) located less than $50 \mathrm{~km}$ from Ouagadougou; (ii) having no more than 75 households; (iii) within $15 \mathrm{~km}$ of other villages within the restricted set 2 Planet Guarantee was not active in any of the selected villages at the time of the

\footnotetext{
${ }^{1}$ At the time of the survey, the exchange rate was about 1 USD for 580 CFA.

${ }^{2}$ In villages with 50 or fewer households, all the households were included in the census. In villages with more than 50 households, the distinct neighbourhoods within the village were identified. Subsequently, the survey team selected one large neighbourhood or some combination of smaller neighbourhoods from the village, ensuring that the sum of households in the selected neighbourhoods was as close to 50 as possible. The census was carried out in these
} 
study although this was not a condition for selection ${ }^{3}$

A household census was conducted in each village, gathering, in particular, information on whether a household had migrant relatives living in the capital city, Ouagadougou. Following the census, a stratified random sample of 20 households were chosen from each village for the rural household survey (the stratification was used to ensure that three-quarters of the sample households in each village had one or more relative in Ouagadougou). The rural survey respondents were asked to list all household members who have left the village, and all migrants based in the capital city Ouagadougou were traced for inclusion in the urban survey. The study began with a rural census to ensure that the sample of rural households to whom the urban migrants are linked is comparable to the rural households that are normally targeted with this type of insurance product.

The rural survey yielded contact information for 246 migrants who were reportedly living in Ouagadougou at the time of the survey. A 'call centre' was set up to contact all of these migrants. The exercise successfully identified 170 migrants currently living in Ouagadougou. The remainder of the migrants had either moved elsewhere (20), could not be contacted (56) or were deceased (1). In the next step, enumerators attempted to visit the Ouagadougou migrants to conduct the urban survey. The survey was conducted over a period of 6 days during which 124 migrants were successfully interviewed. Of the remainder, 25 were temporarily away and 21 had refused to participate in the interview. Thus, the urban migrant survey had an attrition rate of $27.1 \%$.We conduct robustness tests, discussed below, to investigate whether and how this attrition affects our analysis.

All urban migrants successfully traced and interviewed were invited to an hour-long demonstration of Planet Guarantee's existing rainfall insurance product. The demonstrations were followed up by telephone interviews to check whether the respondent would be willing to purchase the product on offer. House visits for the purpose of subscription were carried out for those who expressed interest at the market price ${ }^{4}$

Both the rural and urban surveys included questions on transfers made and received via their social network, experience of adverse shocks in the preceding 5 years, and strategies adopted to cope with the shocks. A key question we aimed to tackle in the study was the marketability of the insurance product to urban migrants, as compared to their rural relatives. Resource constraints and logistical challenges meant that it was not possible to pilot the product with rural farmers or include incentivised willingness-to-pay questions in the rural survey. Nevertheless, a module on

selected neighbourhoods from the village.

${ }^{3}$ The full list of villages, neighbourhoods and number of census households, as well as a map are provided in Table A1 and Figure A1 in the appendix.

${ }^{4}$ In situations where the rural household reported multiple migrant relatives in Ouagadougou, the study team attempted to contact all of them, even if this meant contacting multiple urban migrants linked to the same rural household. Given that urban migrants had the opportunity to discuss the insurance policy with their rural relatives before signing up, urban migrants who shared the same rural relatives would have been able to coordinate their subscription decisions. 
a hypothetical insurance product included in both surveys provides some insights about relative marketability. The respondents in the rural and urban surveys were presented with a hypothetical rainfall index product, described in careful detail, followed by questions to test their understanding of the product and to elicit their willingness-to-pay for such a product. The description of the hypothetical rainfall index product read out to the respondents is included in the appendix.

A focus group discussion (FGD) was conducted with a random sample of urban migrants who were traced as part of the urban survey. This FGD was focused on understanding whether and how effectively they were able to provide assistance to their rural relatives following adverse weather shocks, their experience with formal financial products, their interest in a potential rainfall index insurance product marketed to urban migrants, and how such a product could be tailored to their needs and specific circumstances.

\section{Empirical analysis}

\subsection{Descriptive Analysis}

In this section we use data from the rural census and the rural and urban household surveys to establish some key patterns regarding social ties between rural farm households and urban migrants and the role that these social ties play in helping rural farmers cope with adverse weather shocks.

The census data, summarized in columns 1 and 2 of Table 1 , shows that $56 \%$ of the rural households had at least one relative living in Ouagadougou. Of those, $70 \%$ declared that they had previously received transfers from their Ouagadougou-based relative. The rural household questionnaire included more detailed questions on out-migration from the household shown in columns 3-6 of Table 1. These data reveal that $83 \%$ of rural households had at least one relative over 15 years of age who was previously a household member but has since moved away, either temporarily or permanently. Of these households, about half reported that they have relatives currently living in Ouagadougou and a third that they have relatives in other urban areas. (Recall that the rural

survey was based on a stratified sample, with $\frac{3}{4}$ of the sample drawn from census households with at least one relative in Ouagadougou).

We compare the basic characteristics between the rural (panel A) and the urban (panel B) samples in Table 2. The household characteristics we focus on include household size, gender, age, education, and for the migrants how long they have been living in Ouagadougou. For rural households, we report age, gender and education of the household head. For the urban sample, we report the characteristics of the migrant whose name was reported by the rural relatives.

The data in the table reveal a number of striking differences between rural and urban households. On average, rural households consist of 12 members compared to 6 members on average for urban households, i.e. rural households are twice as large as urban ones. Rural household heads are, 
on average, older and are more likely to be men. Moreover, rural household heads have received less formal education than urban migrants. About $69 \%$ of rural household head report not receiving any form of education. This proportion falls to $27 \%$ among urban migrants. Among urban migrants, $24 \%$ report receiving some elementary school level education, and $46 \%$ report attaining secondary school or higher education. In contrast, $8 \%$ of rural household heads report having attended elementary school and only $2.75 \%$ report having attended secondary school. On average, migrants have been living in Ouagadougou for about 13 years. Given that the average age of migrants is 33 years, one can infer that on average migrants moved to Ouagadougou in their early twenties.

The next question we ask is whether and to what extent urban migrants provide assistance to their rural relatives during adverse weather shocks. The urban survey included questions on whether they had received request for assistance during each of the three years prior to the survey (2014, 2015 and 2016) and, if so, if they had been able to respond to this request for assistance positively. The urban respondents were also asked to assess the level of rainfall during each of those years in terms of agricultural needs. This information allows us to construct Figure 1. The figure shows that while less than $30 \%$ of urban migrants receive requests for assistance from their rural relatives when there is sufficient rainfall, this figure rises to nearly $60 \%$ when the rainfall was thought to be insufficient. In a majority of instances, the urban migrants are able to, and do, respond positively to the request for assistance.

The rural survey also provides corroborative evidence on the importance of transfers from relatives in coping with adverse shocks as demonstrated in Table 3. For the three years preceding the survey (2014-16), rural respondents classified $51.2 \%$ of the years as periods in which they experienced at least one adverse shock. They coped with the shock with a transfer from a relative in $16.3 \%$ of cases, by engaging in asset sales in $31.7 \%$ of cases and did not adopt any coping mechanism in $33.1 \%$ of cases. None of the respondents reported using formal insurance, and less than one percent of the respondents had coped with the shock using credit from a formal institution. These figures suggest that there is potential for relatives of rural farmers to play a greater role in helping with adverse shocks.

The rural survey included questions on the types of adverse shocks experienced during the five years preceding the survey. Figure 2 shows the the distributions of adverse shocks the households report having faced. Among the most commonly reported shocks are droughts (34.75\%) and interruptions in rainfall $(29.25 \%)$ but flooding $(29.75 \%)$ and off-season rains $(35.75 \%)$ appear to be equally important.

Discrepancy in Shock Reports: Urban migrants were asked to report on shocks experienced by their rural relatives. Comparing the reports by the urban migrants and their rural relatives, as shown in Table 4 gives an indication of the knowledge of urban migrants of shocks experienced by rural farmers, necessary criteria for informal risk-sharing. The table shows large differences. Conditional on a report of a shock by the rural farmer, there is only a $30 \%$ probability that the urban 
migrant from the same household would report a shock of the same type, and a $46 \%$ probability that the migrant would report a shock in the same year. The correlation between the farmer's and migrant's shock reports are worse further back in time: using the Pearson's Chi-square test, we cannot reject the null hypothesis that the two sets of reports are independent in the years 2012-2014. We can reject the null hypothesis in 2015 and 2016 but even in 2016 - the year immediately before the survey - the correlation between the two sets of reports stands at 0.35 . Therefore, while the shock reports are likely to be affected by problems of recall, the evidence suggests that the urban migrants lack information about the shocks experienced by their rural relatives 5

In Table 5, we report on two descriptive regressions used to explore the factors behind the discrepancies in shock reports between the urban migrant and the rural farmer. For this purpose, we constructed two measures of discrepancies between the rural farmer and their urban migrant relative in reported shocks. The first measure is a binary indicator for whether there is an inconsistency in reports of shocks that are covered by the insurance policy (e.g. the rural farmer reports a covered shock while the migrant does not or vice versa). The second measure is a binary indicator for whether there is a mismatch in the number of shocks reported by the rural farmer and the urban migrant relative. We use each of these measures as the dependent variable in a linear probability model. As Table 5 shows, the probability of a discrepancy in reports of covered shocks is increasing in the length of time the urban migrant has spent in Ouagadougou. The probability of a discrepancy also appears to be higher between siblings (statistically significant at the $5 \%$ level) and for migrant children (not statistically significant) compared to other types of relations in the sample (niece/nephew, uncle/aunt, son-in-law/daughter-in-law, etc.). No such pattern emerges for discrepancies in the number of shocks reported.

Willingness to Pay for a Hypothetical Insurance Policy: In both surveys, a hypothetical rainfall index insurance policy was described in careful detail to the respondents, followed by questions to test their comprehension. More precisely, enumerators were instructed to read out a text to the respondents that described the product (we provide this text in the appendix). After the product had been described, respondents were asked if they understood how it worked and if they replied negatively the exercise was repeated. When a respondent confirmed that they had understood, they were subject to a short quiz about the product. We compare the performance of urban and rural respondents in Table 6. The performance of the urban and rural migrants were very similar: an average of 1.37 incorrect answers in both cases. In total, $30 \%$ of urban migrants requested that the description of the product be repeated compared to $29 \%$ of rural farmers.

Following the quiz, the respondents were asked if they would be willing to purchase the product

\footnotetext{
${ }^{5}$ For this argument, we assume that rural farmers have a more accurate recall of their shocks than do the urban migrant relatives. We argue that this is a reasonable assumption as the rural farmers experienced these shocks directly, with, in some cases, significant economic loss and major economic decisions such as the sale of assets or cutting back consumption to cope with them. By contrast, the urban migrant experienced only a secondary effect of the shock, for example because of assistance provided to the rural household.
} 
at the market price of 2000 CFA. Those who replied negatively were subsequently asked, in succession, if they would be willing to purchase at a price of 1800, 1600 or 1400 CFA and, if not, at what price they would be willing to buy the product. In both surveys, $83 \%$ of the respondents expressed a willingness to buy the product at $2000 \mathrm{CFA}$. Averaging across the price at which respondents expressed a willingness to buy, urban respondents had a mean WTP of 1840 CFA compared to 1843 CFA for rural farmers.

In Table 7, we report on descriptive regressions used to explore the determinants of the WTP of the urban migrants and the rural farmers. We find that rural farmers who previously experienced a shock covered by the hypothetical insurance product (more precisely, experienced at least one such shock in the previous five years) have a higher WTP (statistically significant at the $5 \%$ level). In contrast, the urban migrants' WTP is not sensitive to the migrants' own report of whether the rural relative previously experienced a shock covered by the hypothetical insurance product (the negative is close to zero and statistically insignificant). The urban migrant's WTP is higher when the migrant reports providing financial assistance to the rural relative to help cope with an adverse shock (statistically significant at the $10 \%$ level). We also find a negative relationship between the WTP of the urban migrant and rural farmer, albeit statistically significant only under some specifications. We reason that such a negative relation is to be expected for the following reason. If an urban migrant has a high WTP, it is likely that he/she provides financial assistance to the rural relative in times of need. This would mean that the latter has relatively low exposure and should, consequently, have a low WTP.

Focus Group Discussions: We summarise here the key remarks to emerge from the focusgroup discussions with the migrant network associations and the random sample of urban migrants:

- An almost universal interest in a rainfall index insurance product marketed at urban migrants provided that the price was within their means;

- Concerns about basis risk and measurement of rainfall at the plot level;

- Indications that they would find the product more attractive if it also covered the risk of flooding and high winds;

- A strong preference that indemnity payments are paid directly to the rural farmers for whom urban subscribers purchase insurance, primarily to avoid the temptation that urban subscribers use the money for other needs before it can be transmitted to their rural relatives;

- A strong preference for individual subscription rather than group subscription.

The feedback from the focus group discussions informed the design of the intervention in a number of ways. The pilot offered individual subscriptions rather than group subscriptions. To investigate the declared preference for insurance payouts being paid directly to the rural farmer, 
two contracts were designed: (a) insurance payouts made to the urban subscriber; (b) insurance payouts made directly to a rural beneficiary indicated in the contract. As mentioned above, the contract on offer was randomised across respondents during the pilot to compare the demand for each. Regarding the stated concerns with basis risk, Planet Guarantee's use of high precision satellite technology to measure rainfall at different stages of the growth cycle would enable the subscribers to define an area of 10 square kilometers that maps onto their relatives' farm plots (see the description of the intervention in Section 2 above) and thus address this issue at least to some extent 6

\subsection{Determinants of Insurance Uptake by Urban Migrants}

As described in Section 3 , during the interviews with urban migrant respondents were invited to a demonstration of Planet Guarantee's standard rainfall index insurance product and to take part in the focus-group discussion on rainfall index insurance. We followed up this event with telephone interviews and, for those who expressed an interest in purchasing an insurance policy, visits at their home or place of work for the purpose of subscription. This exercise lasted two weeks, during which Planet Guarantee's rainfall index insurance had an uptake rate of 27 out of 124, i.e. 21.7\%. For the purpose of comparison, Planet Guarantee's subscription rate in rural areas is between 20 and $35 \%$ but this includes areas where the product has been offered and marketed over several years. By contrast, the subscription offer for urban migrants was made during a tight two-week window, given that policies had to be signed before the rainy season got fully underway. Based on PlaNet Guarantee's administrative data, the cost per subscription among urban migrants ranged from 10,000 to 25,000 CFA. This includes the cost of marketing, phone calls, home visits, etc. In comparison, the initial cost per subscription among rural farmers range from 20,000 to 40,000 CFA.

We conduct an exploratory analysis of the insurance product uptake by urban migrants. We employ simple regression analysis, using a binary dependent variable $(y)$ indicating whether an urban migrant subscribed to the product or not, and the following explanatory variables:

- At the subscription stage, each migrant was randomly offered either to have the insurance provider pay the eventual compensation directly to the rural relative on whose behalf the insurance was purchased, or to pay the compensation to the subscriber. The variable Pay to relative takes a value of 1 in the first case and 0 in the second case.

- How long the migrant has been living in the city of Ouagadougou (Years in Ouagadougou) measured in years. We hypothesize that migrants who moved recently to Ouagadougou may have stronger ties with their household of origin. On the other hand, it is plausible that

\footnotetext{
${ }^{6}$ The focus group discussions were conducted before the details of Planet Guarantee's rainfall index insurance product was demonstrated to the participants.
} 
individuals who have lived in Ouagadougou for a longer period of time would be less financially constrained and, consequently, better able to afford the premium.

- How frequent were crop shocks experienced by the rural household between 2012 and 2016 as reported by the migrant (Frequency of shocks reported by migrant). We hypothesize that migrants who believe (correctly or incorrectly) that their household of origin is often exposed to harvest losses would be likely to purchase the insurance policy.

- How frequent were crop shocks experienced by the rural household between 2012 and 2016 as reported by the rural household (Frequency of shocks reported by household). We hypothesize that if households who face frequent shocks usually turn to their urban relatives for help, then the urban migrant would be likely to purchase the insurance policy.

- Whether the rural household reported receiving financial support from the migrant to cope with negative shocks (Financial support reported by household).

- Whether the migrant reports having provided financial support to the rural farmer to cope with negative shocks during the previous 5 years (Financial support reported by migrant).

- Whether either the rural household or the migrant reports financial support from the former to the latter to cope with negative shocks (Any financial support).

- Whether the shocks (experienced by the rural household) and reported by the migrant are covered by the product (Coverable shock reported by migrant). In our data, only droughts and adverse rainfall distribution would be covered. Other shocks (e.g. illness, pest invasion, bushfire, flooding) are not covered. We hypothesize that the migrant is more likely to purchase the insurance policy if he/she believes that the shocks experienced by his/her relatives most frequently are covered by the policy.

- Whether the shocks (experienced by the rural household) and reported by the household are covered by the product (Coverable shock reported by household). We hypothesize that the migrant is more likely to purchase the insurance policy if the shocks his/her relatives experience most frequently are covered by the policy.

- Whether the urban migrant indicated willingness to pay the hypothetical rainfall index insurance product at the market price during the survey (Migrant willing to pay CFA 2000). We hypothesize that the migrant is more likely to purchase the insurance policy offered if he/she also indicated willingness to pay for the hypothetical product at the market price during the household survey.

- Whether the rural household indicated willingness to pay the hypothetical rainfall index insurance product at the market price during the survey (Rural household willing to pay 2000 
$C F A$ ). We introduce this explanatory variable for the purpose of comparison with Migrant willing to pay CFA 2000.

- The number of occasions during the previous 5 years that the rural farmer reported an adverse shock and the urban migrant reported providing financial assistance in response to a request for help (Reporting accuracy). We hypothesize that the migrant is more likely to purchase the insurance if he/she has previously provided financial assistance to the rural farmer in response to a request for help.

- Whether the insurance product was marketed to another migrant related to the same rural farmer (Marketed to multiple migrants). We hypothesize that the migrant is more likely to purchase the insurance if multiple migrants related to the same rural farmer put pressure on one another to do so.

- Whether the insurance product was purchased by another migrant related to the same rural farmer (Purchased by other migrants). We expect the coefficient on this variable to be negative if multiple migrants related to the same rural farmer coordinate their purchase decisions.

Because we have a relatively small sample of observations (124 urban migrants) and relatively few clusters (20 villages), we introduce the variables described above individually in order to keep the specifications parsimonious - with the exception of Pay to relative which appears in each specification. In addition, we control for the relationship between the migrant and the rural household head in each specification 7 Table 8 shows the estimates for each specification. In this table and subsequent regression tables, we report the robust standard errors of the point estimates and the bootstrapped pvalues of the null hypothesis that the point estimate is zero. Since we randomized at the migrant level, the nonclustered estimates are accurate when focusing only on the particular sample of individuals we use for the estimation (Abadie et al. 2017). When commenting on the entire population from which the 20 villages are selected, the bootstrapped pvalues adjusted for the village level clustering provide the correct inference.

We find that the coefficient for Pay to relative consistently has a positive and statistically significant effect on uptake, i.e. migrants who were offered the product in which insurance payouts were made directly to the rural farmer were more likely to purchase. Our estimates remain statistically significant at least at the $10 \%$ level even when we generalize to the entire population from which the 20 villages are drawn. As this feature of the insurance policy was randomised, the coefficient of pay_to_relative can be given a causal interpretation: i.e. offering insurance payments directly to the rural farmer increases uptake of the policy by their urban migrant relatives.

Next, we discuss how the probability of purchase of the insurance policy by the urban migrant is correlated with other characteristics of the migrant and the rural farmer. While these correlates

\footnotetext{
${ }^{7}$ In practice, we control for whether the migrant is a child of the household head, or the household head's sibling.
} 
do not necessarily imply a causal relationship, they are suggestive of the various drivers of demand for rainfall index insurance among urban migrants.

Migrants who reported a higher number of shocks (Frequency of shocks reported by migrant), or reported at least one coverable shock (Coverable shock reported by migrant), experienced by their rural relative were more likely to purchase (coefficients statistically significant at the $10 \%$ level). However, the corresponding reports from the rural households themselves have no effects on uptake (coefficients are slightly negative and statistically insignificant). This pattern suggests that there is informational asymmetry about shocks experienced by the rural household, and the urban migrant's purchase decision is sensitive to his/her own perception or memory of shocks experienced by the rural farmer, but not to the rural relatives' own reports.

Migrants who report providing financial assistance that coincide with shock reports by rural relatives (Reporting accuracy) were more likely to purchase: each 'accurate payout' increases the probability of insurance uptake by the urban migrant by about $14 \mathrm{pp}$ (coefficient statistically significant at the $10 \%$ level). In cases of migrant-farmer pairs where either party reported a transfer from the migrant to the farmer to cope with adverse shocks (Any financial support), the migrant was also more likely to purchase the insurance policy (coefficient statistically significant at the 5\% level; if we construct the variable based on reports from one party only, Financial support reported by household or Financial support reported by migrant, the corresponding coefficients are positive but not statistically significant). These estimates suggest that the demand for formal insurance is higher if the urban migrant already provides financial assistance to their rural relatives in their times of need.

The probability of insurance uptake by a migrant is considerably higher if the marketing campaign included other migrants linked to the same rural farmer, but lower if another migrant has purchased the insurance policy (coefficients of Marketed to multiple migrants and Purchased by other migrants statistically significant at the $10 \%$ and $1 \%$ levels respectively). This suggests that urban migrants linked to the same rural household do coordinate their decisions, potentially pressuring one another to purchase the insurance policy; and becoming less likely to purchase the policy oneself if another urban relative has done so 8

To explore possible heterogeneity of the effects of the "pay to relative" offer on uptake of the product, in Table 9, we report on estimations where the Pay to relative variable is interacted, one at a time, with the other explanatory variables. In most instances, the estimated interaction coefficients are statistically insignificant with two exceptions. We find that the longer a migrant has lived in Ouagadougou, the weaker is the effect of the "pay to relative" offer on uptake, while its effect is stronger if the rural household reported a coverable shock.

The estimates in Table 10 show that, at the sample mean, the effect of the "pay to relative" offer

\footnotetext{
${ }^{8}$ In the data we find only one instance where a rural household is 'doubly' insured because of subscription by two urban migrant relatives. However, lack of coordination among urban migrant relatives leading to excessive subscription may be a concern if such a marketing strategy is scaled up or implemented in other contexts.
} 
on uptake is positive and statistically significant, consistently in the range $16-20 \%$. Turning to the other explanatory variables, we again find the pattern that the probability of uptake is increasing in the migrant's report of the number of adverse shocks experienced by the household but is unaffected by the rural household's own reports. Similarly, we find that uptake is significantly higher if the migrant reported a coverable shock but the corresponding effect for the rural household's own report of a coverable shock is statistically insignificant.

\section{Robustness Checks: Sample Selection}

A potential concern is that the urban migrants included in the regressions could be different from the ones who could not be tracked. As a consequence, the estimates reported above may be biased. For example, if migrants who are successfully tracked are more likely to subscribe to the policy than migrants who were not found, then we may be overstating the uptake rate. To assess the extent of this sample selection issue, we start by using information on the urban migrants collected from their rural relatives to compare the migrants who were found with the ones who were not. We summarise these comparisons and test for their statistical significance in Table A2 in the appendix. The differences are statistically significant at least at the $10 \%$ level for variables indicating whether the migrant is reported to have some investment in the village, has provided some financial support within the past five years, is a sibling of the rural household head, is male or is a formal sector employee.

In Table 11 we report alternatives of Table 8 where we adjust for the sample selection 9 In panel $\mathrm{A}$, we control for the variables listed in Table $\mathrm{A} 2{ }^{10}$ In Panels B and C, we use probability inverse weighting (Wooldridge, 2010, 2002) to correct for selection bias using the probability estimates in Table A3, columns 1 and 2 respectively (in column 2, we add village dummies to the model). Thus, the estimates in Panels B and C give more weight to migrants with characteristics similar to those who could not be tracked relative to those who were in fact tracked. Overall, the point estimates in Panels A-C remain very similar to those reported in Table 8 . While this pattern does not rule out sample selection bias entirely, it is reassuring that the estimates remain remarkably similar across the different specifications. Moreover, the robustness check estimates should be interpreted with caution given the small sample size.

\section{Discussion}

The findings from the pilot intervention described in this paper provide significant evidence regarding the potential for using urban migrants for channeling weather index insurance to small-scale rural farmers in a developing country.

\footnotetext{
${ }^{9}$ The full set of the regressions are shown in Tables $\mathrm{A} 4 \mathrm{~A} 5$ and $\mathrm{A} 6$ in the appendix.

${ }^{10}$ The list of control variables does not include 'financial support', 'biological child' and 'sibling' since these variables are already in the regressions. Notice that the family relation variables here are reported by the rural respondent while these variables are reported by the urban migrant in Tables 89 and 11
} 
First, we provide evidence on linkages between rural households in villages close to Ouagadougou (within a $50 \mathrm{~km}$ radius) and urban migrants from these villages presently residing in Ouagadougou: $56 \%$ of rural households have a relative residing in Ouagadougou; and about $70 \%$ of them receive transfers from a Ouagadougou-based relative (Table 1). These proportions are potentially lower for villages located further from Ouagadougou but they do not take into account relatives living in other major cities (e.g. Bobo-Dioulasso and Koudougou). Using survey data on Ouagadougoubased migrants from the same villages, we find that about 30\% receive requests for assistance from rural relatives in years that the rains have been sufficient for agriculture, and this figure rises to nearly $60 \%$ when the rains have been insufficient (Figure 1).

Second, we provide evidence of significant demand for rainfall index insurance from urban migrants with relatives in rural areas: with an uptake rate of $22 \%$ during a two-week window following a demonstration of the insurance product. The uptake rate is higher for migrants who have recently arrived in Ouagadougou and for migrants who reported that their rural relative had experienced an adverse shock during the previous 5 years (Tables 8 and 9 . For the purpose of comparison, Planet Guarantee's subscription rate in rural areas is between 20 and $35 \%$ but this includes areas where the product has been offered and marketed over several years. Thus, the cost per subscription during the urban pilot was $38-50 \%$ lower, which suggests that marketing formal insurance to rural farmers via urban migrants can potentially improve its cost-effectiveness."

The study involved the randomisation of one feature of the insurance policy: half the urban migrants in the study were offered an insurance policy in which payouts would be made, not to the subscriber, but directly to the intended beneficiary. This feature increased uptake rates by 17-22 percentage points (Tables 8 and 11. This was consistent with findings from the focus group discussions, where urban migrants explained that they preferred this option because of the possible temptation to use an insurance payout, intended for their rural relative, for some other purpose. It demonstrates that formal insurance products can address issues related to temptation and selfcontrol in informal risk-sharing networks and the subscribers are aware of this potential.

We found large differences in adverse shock reports by rural farmers and reports of the same shocks by their urban relatives. The uptake rate of the marketed insurance policy was higher when the migrant reported that their rural relative had experienced at least one adverse shock - covered by the insurance policy - during the preceding 5 years; but the uptake rate did not respond to the incidence of such shocks as reported by the relatives themselves. A similar pattern emerges when we use the "total number of shocks" in lieu of "at least one coverable shock". There are two explanations that suggest themselves. The first is that the urban migrant does not have as good a recollection of the shocks suffered as their rural relatives. The second is that the urban migrant does not trust the shock reports that he or she obtains from the rural relatives.

If either explanation holds true, a marketing strategy where urban migrants are given information about the weather-related incidents in their villages of origin would help them make better 
decisions regarding the purchase of the insurance policy, and potentially improve uptake. The evidence also points to important informational asymmetries about weather shocks between urban migrants and their rural relatives which would hinder informal risk-sharing. The rainfall index insurance product, by providing third-party verification of these shocks would remove these informational asymmetries and thus improve the scope for risk-sharing.

An important question related to the marketing of weather index insurance to urban migrants that that we do not explore in this study is whether the insurance provider should inform rural farmers about the insurance policies purchased on their behalf (in our intervention, the insurance provider did not communicate this information). Urban migrant subscribers may refrain from communicating this information to their rural relatives themselves to avoid excessive demands for transfers during periods of insufficient rain. However such information may have important effects on the farmers' ex-ante risk management behaviour. There is a potential trade-off between uptake of the insurance product by the urban migrant (they may find the product more attractive if they can control the information flow) and the ex-ante impact on risk management behaviour (which would be maximised if the rural farmers are systematically told by the insurance provider about the insurance purchased on their behalf). We hope that future research can shed light on these trade-offs.

In the absence of perfect risk-sharing between urban migrants and rural relatives (as shown in Table 3 rural respondents coped with adverse shocks with transfers from a relative only a fraction of the time), whether marketing rainfall index insurance to urban migrants would be an effective strategy for improving social protection of rural farmers also requires consideration.

It is important to note that perfect risk-sharing between urban migrants and rural farmers is not a pre-requisite for rural households to benefit from formal insurance obtained by their urban migrant relatives. Rather, the key question is whether urban migrants are willing to insure their rural relatives for the specific type of shocks for which the policy triggers payments. Figure 1 shows that urban migrants are, indeed, more likely to provide assistance for more severe rainfall shocks. The qualitative evidence from the focus group discussions also suggest that urban migrants would provide more assistance to their rural relatives when they experience shocks if the former were not liquidity constrained.

In this context, our findings regarding the insurance policy that involved insurance payouts made directly to the rural farmer are also significant. The effectiveness of this insurance policy in providing protection to rural households does not depend on the extent of risk-sharing between urban migrants and rural farmers. Nor did the feature of direct payments to the rural farmer dissuade urban migrants from purchasing this policy. On the contrary, as our findings show, urban migrants were more likely to purchase insurance when offered a policy with this feature. 


\section{References}

Abadie, A., Athey, S., Imbens, G. W., and Wooldridge, J. (2017). When should you adjust standard errors for clustering? Working Paper 24003, National Bureau of Economic Research.

Banerjee, A. and Mullainathan, S. (2010). The shape of temptation: Implications for the economic lives of the poor. Technical Report w15973, National Bureau of Economic Research.

Batista, C. and Narciso, G. (2016). Migrant remittances and information flows: evidence from a field experiment. The World Bank Economic Review, 32(1):203-219.

Beauchemin, C. (2011). Rural-urban migration in West Africa: towards a reversal? migration trends and economic situation in Burkina Faso and Côte d'ivoire. Population, Space and Place, 17(1):47-72.

Beauchemin, C. and Bocquier, P. (2004). Migration and urbanisation in Francophone West Africa: An overview of the recent empirical evidence. Urban Studies, 41(11):2245-2272.

Berg, A., Quirion, P., and Sultan, B. (2009). Weather-index drought insurance in Burkina-Faso: assessment of its potential interest to farmers. Weather, Climate, and Society, 1(1):71-84.

Binswanger, H. and Rosenzweig, M. (1993). Wealth, weather risk and the composition and profitability of agricultural investments. Economic Journal, 103(416):56-78.

Binswanger-Mkhize, H. P. (2012). Is there too much hype about index-based agricultural insurance? Journal of Development Studies, 48(2):187-200.

Cole, S., Jagnani, M., Nestor, L., and Tobacman, J. (2013). Marketing weather-indexed agricultural insurance to smallholder farmers in rural Gujarat, India. International Growth Centre Policy Brief, 13:0880.

Dercon, S. (2002). Income risk, coping strategies, and safety nets. The World Bank Research Observer, 17(2):141-166.

Dercon, S., Hill, R. V., Clarke, D., Outes-Leon, I., and Taffesse, A. S. (2014). Offering rainfall insurance to informal insurance groups: Evidence from a field experiment in Ethiopia. Journal of Development Economics, 106:132-143.

Dustmann, C., Fasani, F., Meng, X., and Minale, L. (2017). Risk attitudes and household migration decisions. IZA Working Paper, 10603.

Fafchamps, M. and Lund, S. (2003). Risk-sharing networks in rural Philippines. Journal of Development Economics, 71(2):261-287. 
Gaurav, S., Cole, S., and Tobacman, J. (2011). Marketing complex financial products in emerging markets: Evidence from rainfall insurance in India. Journal of Marketing Research, 48(SPL):S150-S162.

Giné, X., Townsend, R., and Vickery, J. (2008). Patterns of rainfall insurance participation in rural India. The World Bank Economic Review, 22(3):539-566.

Kazianga, H. (2006). Motives for household private transfers in Burkina Faso. Journal of Development Economics, 79(1):73-117.

Kazianga, H. and Udry, C. (2006). Consumption smoothing? Livestock, insurance and drought in rural Burkina Faso. Journal of Development Economics, 79(2):413-446.

Ligon, E., Thomas, J. P., and Worrall, T. (2002). Informal insurance arrangements with limited commitment: Theory and evidence from village economies. The Review of Economic Studies, 69(1):209-244.

Lucas, R. E. (1997). Internal migration in developing countries. In Rosenzweig, M. R. and Stark, O., editors, Handbook of population and family economics, pages 721-798. Elsevier.

Matul, M., McCord, M. J., Phily, C., and Harms, J. (2010). The landscape of microinsurance in Africa. International Labor Organization.

Mobarak, A. M. and Rosenzweig, M. R. (2012). Selling formal insurance to the informally insured. Yale Economics Department Working Paper, (97).

Mobarak, A. M. and Rosenzweig, M. R. (2013). Informal risk sharing, index insurance, and risk taking in developing countries. American Economic Review, 103(3):375-80.

Morduch, J. (1995). Income smoothing and consumption smoothing. Journal of Economic Perspectives, 9(3):103-114.

Platteau, J.-P. (1997). Mutual insurance as an elusive concept in traditional rural communities. The Journal of Development Studies, 33(6):764-796.

Potts, D. (2008). Recent trends in rural-urban and urban-rural migration in Sub-Saharan Africa: The empirical evidence and implications for understanding urban livelihood insecurity. Environment, Politics and Development Working Paper Series, Paper, 6.

Rosenzweig, M. R. and Stark, O. (1989). Consumption smoothing, migration, and marriage: Evidence from rural India. Journal of Political Economy, 97(4):905-926.

Scott, J. C. (1977). The moral economy of the peasant: Rebellion and subsistence in Southeast Asia. Yale University Press. 
Seshan, G. and Zubrickas, R. (2017). Asymmetric information about migrant earnings and remittance flows. The World Bank Economic Review, 31(1):24-43.

Stark, O. and Lucas, R. E. (1988). Migration, remittances, and the family. Economic Development and Cultural Change, 36(3):465-481.

Townsend, R. M. (1994). Risk and insurance in village India. Econometrica, 62(3):539-591.

Udry, C. (1994). Risk and insurance in a rural credit market: An empirical investigation in northern Nigeria. The Review of Economic Studies, 61(3):495-526.

Wooldridge, J. M. (2002). Inverse probability weighted m-estimators for sample selection, attrition, and stratification. Portuguese Economic Journal, 1(2):117-139.

Wooldridge, J. M. (2010). Econometric analysis of cross section and panel data. MIT press.

Yang, D. and Choi, H. (2007). Are remittances insurance? evidence from rainfall shocks in the Philippines. The World Bank Economic Review, 21(2):219-248. 
Figure 1: Assistance from Urban Migrants vs Rainfall Shortage

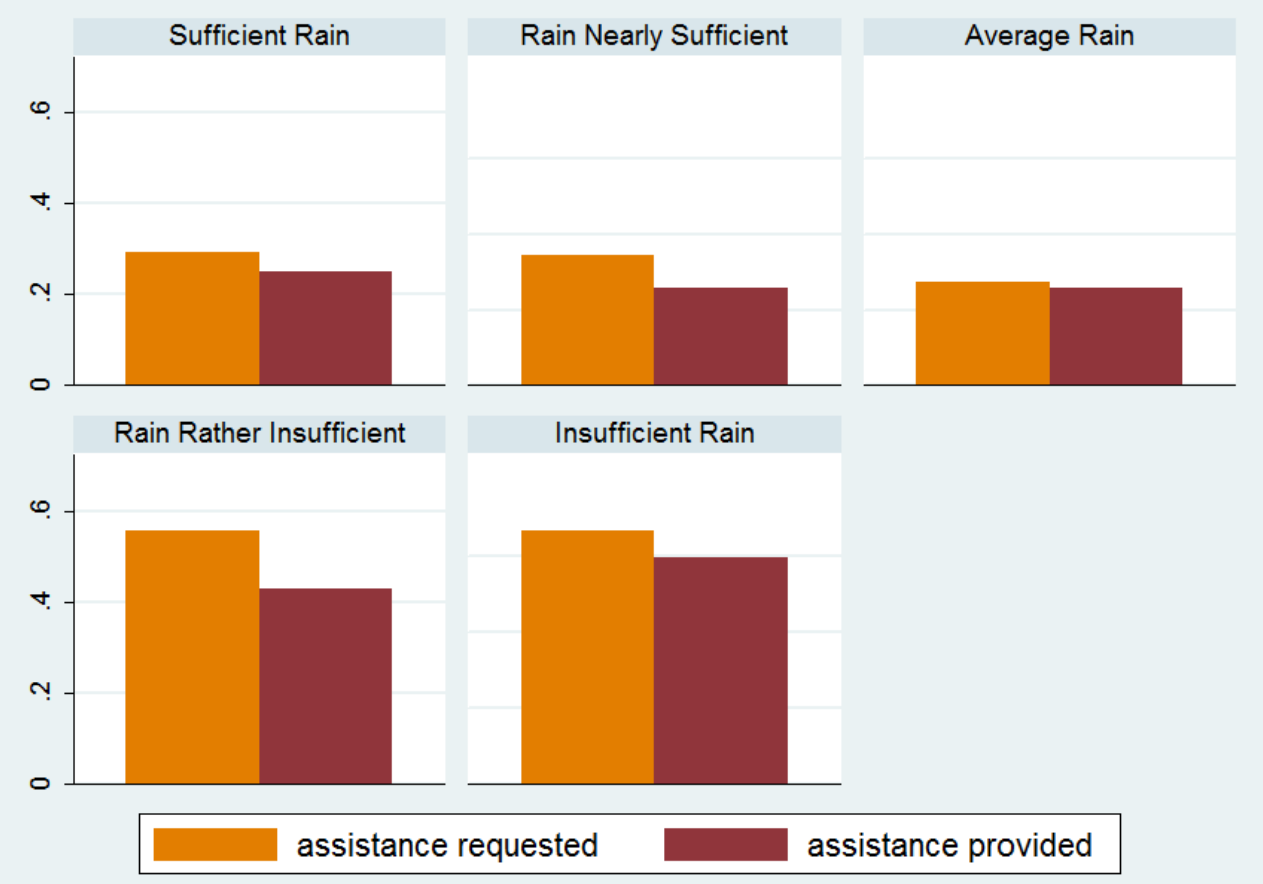


Figure 2: Types of Shocks Faced by Farmers

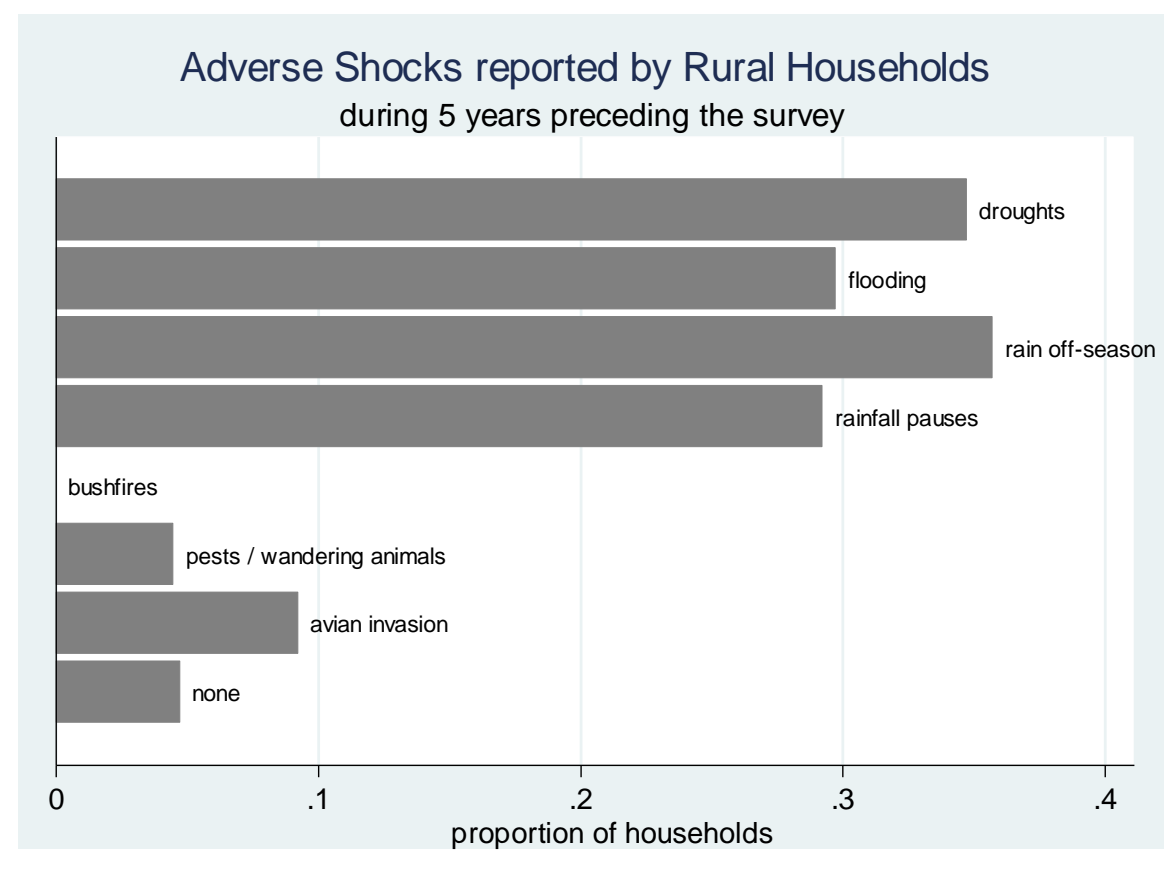


Table 1: Migrant Link Information from Rural Census

\begin{tabular}{|c|c|c|c|c|c|c|}
\hline & \multicolumn{2}{|r|}{$(2)$} & $(3)$ & (4) & $(5)$ & (6) \\
\hline & \multicolumn{2}{|c|}{ Rural census: household } & \multicolumn{3}{|c|}{ Rural household survey: \% households with } & \multirow[t]{2}{*}{ \# Ouga migrants (if $>0$ ) } \\
\hline & $\begin{array}{c}\text { has relatives } \\
\text { in Ouaga }\end{array}$ & $\begin{array}{l}\text { receives transfers } \\
\text { from relative }\end{array}$ & with migrants & migrants in Ouaga & $\begin{array}{l}\text { migrants in other } \\
\text { urban areas }\end{array}$ & \\
\hline $\begin{array}{l}\text { mean } \\
95 \% \text { conf. int. } \\
\mathrm{N}\end{array}$ & $\begin{array}{c}0.56 \\
{[0.53-0.59]} \\
978\end{array}$ & $\begin{array}{c}0.70 \\
{[0.66-0.74]} \\
546\end{array}$ & $\begin{array}{c}0.83 \\
{[0.79-0.87]} \\
400\end{array}$ & $\begin{array}{c}0.43 \\
{[0.38-0.47]} \\
400\end{array}$ & $\begin{array}{c}0.32 \\
{[0.27-0.37]} \\
400\end{array}$ & $\begin{array}{c}1.45 \\
{[1.34-1.56]} \\
170\end{array}$ \\
\hline
\end{tabular}

Source: Authors' calculations using survey data 
Table 2: Descriptive Statistics for Rural and Urban Samples

\begin{tabular}{|c|c|c|c|c|c|c|c|c|c|c|c|}
\hline & \multirow{2}{*}{$\begin{array}{l}\text { Household } \\
\text { size }\end{array}$} & \multirow{2}{*}{$\begin{array}{l}\text { Head age } \\
\text { (years) }\end{array}$} & \multirow{2}{*}{$\begin{array}{l}\text { Female } \\
\text { head }(\%)\end{array}$} & \multirow{2}{*}{$\begin{array}{l}\text { Years in } \\
\text { Ouagadougou }\end{array}$} & \multicolumn{6}{|c|}{ Education } & \multirow[b]{2}{*}{$\mathrm{N}$} \\
\hline & & & & & None & Elementary & Secondary & Higher Ed. & Koranic & Literacy & \\
\hline Panel A: Rural Sample & $\begin{array}{l}11.48 \\
(7.18)\end{array}$ & $\begin{array}{c}53.2 \\
(16.21)\end{array}$ & 9.68 & NA & 69.25 & 8 & 2.75 & - & 14.25 & 5.75 & 400 \\
\hline Panel B: Urban Sample & $\begin{array}{c}5.59 \\
(3.54)\end{array}$ & $\begin{array}{c}34.29 \\
(10.87)\end{array}$ & 22.76 & $\begin{array}{c}13.03 \\
(11.25)\end{array}$ & 26.83 & 24.39 & 39.02 & 7.32 & 2.44 & - & 124 \\
\hline
\end{tabular}

Source: Authors' calculations using survey data

Standard deviations in parentheses 
Table 3: Rural Households Risk-Coping Mechanisms (2014-2016)

\begin{tabular}{lr}
\hline & Perctentage \\
\hline household experienced shock & 51.2 \\
$\quad$ household coped with shock with & \\
asset sales & 31.7 \\
help from relations & 16.3 \\
formal credit & 0.9 \\
other measures & 26.2 \\
nothing & 33.1 \\
$\mathrm{~N}$ & 1,128 \\
\hline Source: Authors' calculations using survey data
\end{tabular}


Table 4: Comparing Farmer Shock Reports by Rural Farmer \& Urban Migrant

\begin{tabular}{crr}
\hline & shocks by type & shocks by year \\
\hline both urban migrant + rural farmer & 52 & 94 \\
rural farmer only & 121 & 111 \\
urban migrant only & 106 & 107 \\
neither & 589 & 308 \\
\hline prob(urban 0 - rural 0)1 & 0.847 & 0.742 \\
prob(urban 1 - rural 1)2 & 0.301 & 0.459 \\
correlation coefficient & 0.153 & 0.202 \\
Pearson's Chi2 & 20.39 & 25.23 \\
Source: Authors' calculations using survey data. Note: Table shows number of agricultural shocks reported by an urban \\
migrant and the migrant's rural relatives. In the first column, each report corresponds to a shock type and in the second \\
column each report corresponds to a year in which a shock was experienced. \\
1. Probability of no shock report by urban migrant conditional on no rural report. \\
2. Probability of a shock report by urban migrant conditional on a rural report.
\end{tabular}


Table 5: Determinants of Discrepancies in Exposure to Shocks Reported by Rural Households and their Urban Relatives

(1)

(2)

\begin{tabular}{|c|c|c|}
\hline Dependent Variable: & Discrepancy in Reports of Covered Shocks & Discrepancy in Reports of Frequency of Shocks \\
\hline \multirow[t]{3}{*}{ Sibling } & $0.309^{* *}$ & 0.064 \\
\hline & $(0.143)$ & $(0.155)$ \\
\hline & {$[0.021]$} & {$[0.657]$} \\
\hline \multirow[t]{3}{*}{ Child } & 0.166 & -0.023 \\
\hline & $(0.137)$ & $(0.157)$ \\
\hline & {$[0.213]$} & {$[0.874]$} \\
\hline \multirow[t]{3}{*}{ Migrant invested in village } & 0.148 & -0.142 \\
\hline & $(0.137)$ & $(0.145)$ \\
\hline & {$[0.280]$} & {$[0.295]$} \\
\hline \multirow[t]{3}{*}{ Years in Ouagadougou } & $0.273^{* * *}$ & -0.049 \\
\hline & $(0.088)$ & $(0.107)$ \\
\hline & {$[0.005]$} & {$[0.613]$} \\
\hline \multirow[t]{3}{*}{ Years in Ouagadougou squared } & $-0.044 * * *$ & 0.017 \\
\hline & $(0.016)$ & $(0.020)$ \\
\hline & {$[0.071]$} & {$[0.356]$} \\
\hline \multirow[t]{2}{*}{ Constant } & -0.049 & $0.657 * * *$ \\
\hline & $(0.142)$ & $(0.165)$ \\
\hline Observations & 123 & 123 \\
\hline R-squared & 0.355 & 0.171 \\
\hline
\end{tabular}

Source: Authors' calculations using survey data

Robust standard errors in parentheses. Bootstrapped p-values in brackets. The null hypothesis is that the point estimate is zero.

***: significant at the $1 \%$ level, $* *$ : significant at the $5 \%$ level, *: significant at the $10 \%$ level. 
Table 6: Comparing WTP Responses of Rural farmers and Urban Migrants

\begin{tabular}{lrrrr}
\hline & urban & $95 \%$ conf. int. & rural & $95 \%$ conf. int. \\
\hline explained more than once & 0.30 & {$[0.22-0.38]$} & 0.29 & {$[0.24-0.33]$} \\
\# incorrect answers & 1.37 & {$[1.27-1.48]$} & 1.37 & {$[1.30-1.43]$} \\
contract interesting & 0.96 & {$[0.92-0.99]$} & 0.94 & {$[0.92-0.97]$} \\
willing to pay 2000 CFA & 0.83 & {$[0.76-0.90]$} & 0.83 & {$[0.80-0.87]$} \\
mean WTP in CFA & 1840 & {$[1766-1913]$} & 1843 & {$[1803-1882]$} \\
\hline
\end{tabular}

Source: Authors' calculations using survey data 
Table 7: Determinants of WTP of Rural Households and Urban Migrants

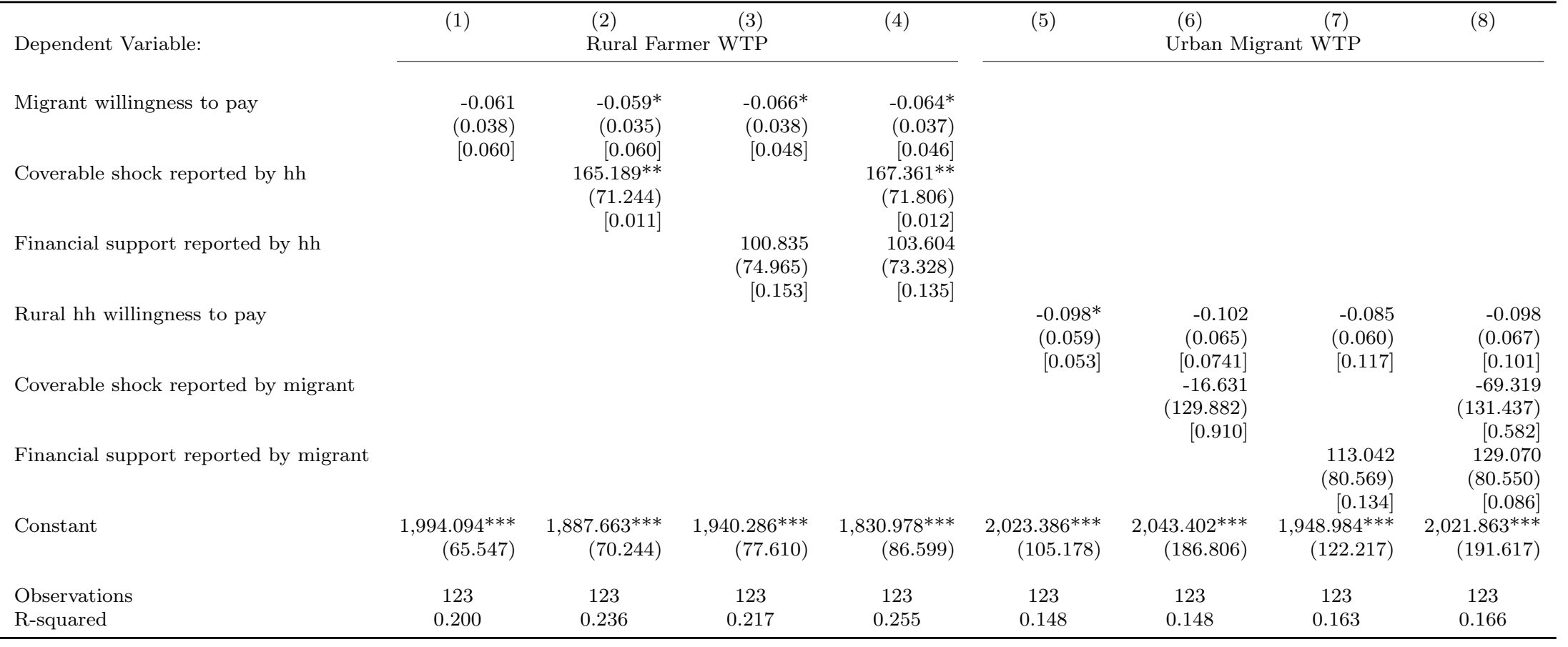

Source: Authors' calculations using survey data

Robust standard errors in parentheses. Bootstrapped p-values in brackets. The null hypothesis is that the point estimate is zero.

***: significant at the $1 \%$ level, ${ }^{* *}$ : significant at the $5 \%$ level, *: significant at the $10 \%$ level. 
Table 8: Determinants of Take-Up of Rainfall Indexed Insurance by Urban Migrants

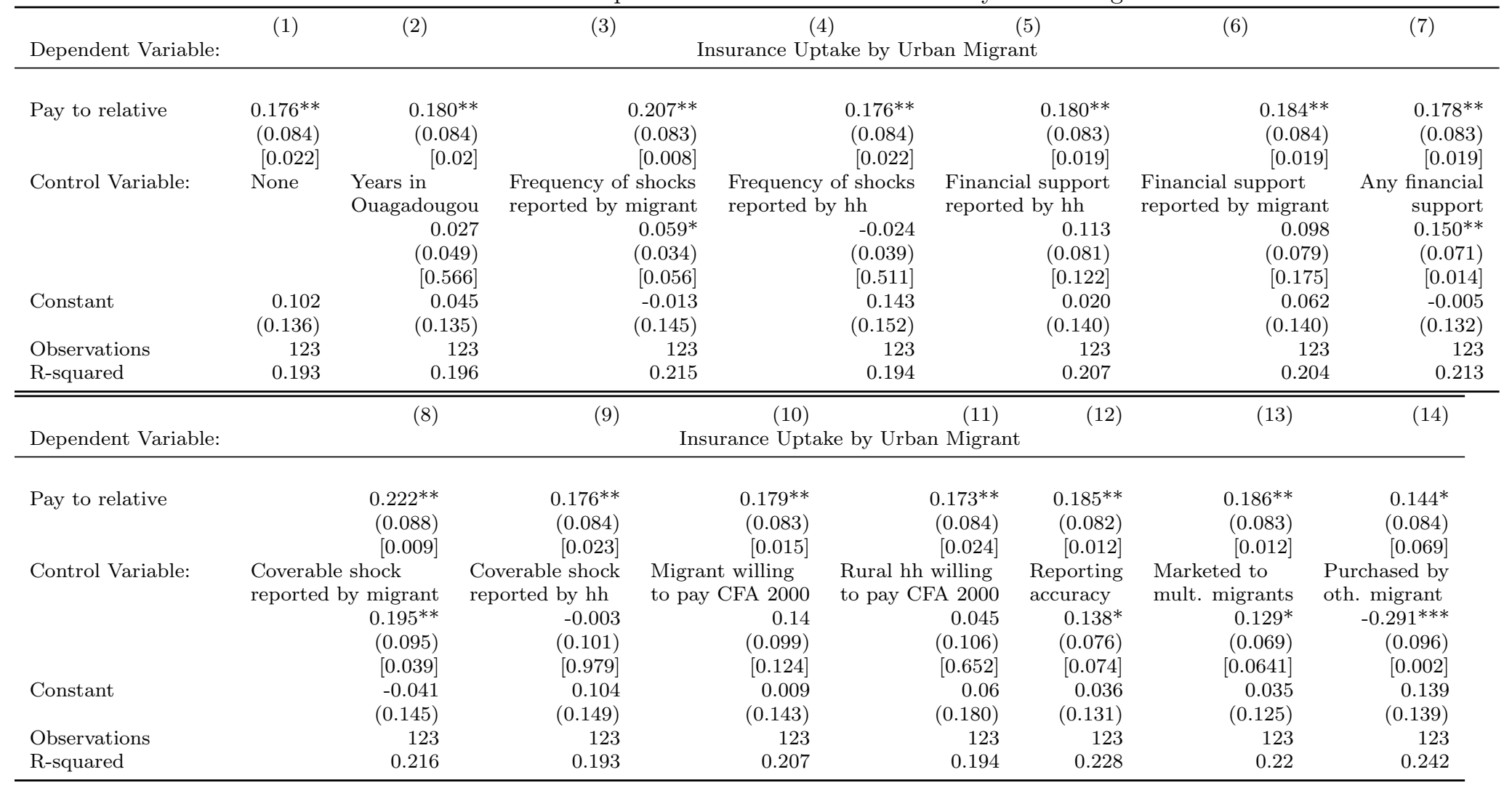

Source: Authors' calculations using survey data

Robust standard errors in parentheses. Bootstrapped p-values in brackets. The null hypothesis is that the point estimate is zero.

***: significant at the $1 \%$ level, **: significant at the $5 \%$ level, *: significant at the $10 \%$ level. 
Table 9: Heterogeneity Analysis of the Take-up of Rainfall Indexed Insurance by Urban Migrants

\begin{tabular}{|c|c|c|c|c|c|c|c|}
\hline Dependent Variable: & \multicolumn{2}{|l|}{ (1) } & \multicolumn{2}{|c|}{$\begin{array}{c}(3) \\
\text { Insurance Uptake by Urban Migrant }\end{array}$} & \multicolumn{2}{|c|}{$(5)$} & (6) \\
\hline \multirow[t]{3}{*}{ Pay to relative } & $0.400 * * *$ & $0.218^{*}$ & 0.171 & 0.128 & & $0.166^{*}$ & 0.209 \\
\hline & $(0.127)$ & $(0.129)$ & $(0.166)$ & $(0.126)$ & & $(0.099)$ & $(0.132)$ \\
\hline & {$[0.000]$} & {$[0.0821]$} & {$[0.274]$} & {$[0.259]$} & & {$[0.0751]$} & {$[0.0851]$} \\
\hline \multirow[t]{5}{*}{ Control Variable: } & Years in & ency of shocks & Frequency of shocks & Financial support & Financial & support & financial \\
\hline & Ouagadougou & ted by migrant & reported by hh & reported by hh & reported b & y migrant & support \\
\hline & 0.09 & 0.062 & -0.025 & 0.071 & & 0.077 & 0.171 \\
\hline & $(0.056)$ & $(0.047)$ & $(0.063)$ & $(0.114)$ & & $(0.112)$ & $(0.111)$ \\
\hline & {$[0.126]$} & {$[0.171]$} & {$[0.655]$} & {$[0.482]$} & & {$[0.460]$} & [0.095] \\
\hline \multirow[t]{3}{*}{ Pay to relative X Control Variable } & $-0.172^{* *}$ & -0.007 & 0.003 & 0.083 & & 0.047 & -0.041 \\
\hline & $(0.076)$ & $(0.069)$ & $(0.076)$ & $(0.163)$ & & $(0.176)$ & $(0.168)$ \\
\hline & {$[0.052]$} & {$[0.917]$} & {$[0.969]$} & {$[0.563]$} & & {$[0.805]$} & {$[0.806]$} \\
\hline \multirow[t]{2}{*}{ Constant } & -0.092 & -0.02 & 0.146 & 0.058 & & 0.074 & -0.025 \\
\hline & $(0.137)$ & $(0.170)$ & $(0.178)$ & $(0.158)$ & & $(0.148)$ & $(0.146)$ \\
\hline Observations & 123 & 123 & 123 & 123 & & 123 & 123 \\
\hline R-squared & 0.233 & 0.215 & 0.194 & 0.209 & & 0.205 & 0.213 \\
\hline F-Stat. joint signficance & 3.395 & 2.783 & 1.542 & 2.048 & & 2.154 & 3.134 \\
\hline $\mathrm{p}$ value & 0.021 & 0.045 & 0.209 & 0.112 & & 0.098 & 0.029 \\
\hline boots. p & 0.038 & 0.034 & 0.133 & 0.079 & & 0.082 & 0.021 \\
\hline \multirow[b]{2}{*}{ Dependent Variable: } & \multirow{2}{*}{\multicolumn{7}{|c|}{$\begin{array}{c}(10) \\
\text { Insurance Uptake by Urban Migrant }\end{array}$}} \\
\hline & & & & & & & \\
\hline \multirow{3}{*}{ Pay to relative } & $0.273^{*}$ & -0.117 & 0.057 & 0.169 & $0.197^{* *}$ & 0.105 & 0.146 \\
\hline & $(0.153)$ & $(0.137)$ & $(0.164)$ & $(0.193)$ & $(0.091)$ & $(0.103)$ & $(0.093)$ \\
\hline & {$[0.0591]$} & {$[0.352]$} & {$[0.708]$} & {$[0.438]$} & {$[0.024]$} & {$[0.260]$} & {$[0.090]$} \\
\hline \multirow[t]{5}{*}{ Control Variable: } & Coverable shock & Coverable shock & Migrant willing & Rural hh willing & Reporting & Marketed to & Purchased by \\
\hline & reported by migrant & reported by hh & to pay CFA 2000 & to pay CFA 2000 & accuracy & mult. migrants & oth. migrant \\
\hline & $0.237^{*}$ & -0.205 & 0.067 & 0.043 & 0.153 & 0.070 & $-0.287^{* * *}$ \\
\hline & $(0.120)$ & $(0.128)$ & $(0.146)$ & $(0.131)$ & $(0.101)$ & $(0.135)$ & $(0.089)$ \\
\hline & {$[0.040]$} & {$[0.0931]$} & [0.619] & {$[0.755]$} & {$[0.192]$} & {$[0.577]$} & {$[0.000]$} \\
\hline \multirow[t]{3}{*}{ Pay to relative X Control Variable } & -0.063 & $0.459 * * *$ & 0.144 & 0.006 & -0.036 & 0.157 & -0.017 \\
\hline & $(0.190)$ & $(0.172)$ & $(0.196)$ & $(0.211)$ & $(0.150)$ & $(0.197)$ & $(0.235)$ \\
\hline & {$[0.712]$} & {$[0.008]$} & {$[0.437]$} & {$[0.977]$} & {$[0.809]$} & {$[0.379]$} & [0.949] \\
\hline \multirow[t]{2}{*}{ Constant } & -0.087 & 0.283 & 0.059 & 0.062 & 0.028 & 0.072 & 0.138 \\
\hline & $(0.193)$ & $(0.170)$ & $(0.152)$ & $(0.185)$ & $(0.137)$ & $(0.127)$ & $(0.142)$ \\
\hline Observations & 123 & 123 & 123 & 123 & 123 & 123 & 123 \\
\hline R-squared & 0.216 & 0.247 & 0.210 & 0.194 & 0.228 & 0.234 & 0.242 \\
\hline F-Stat. joint signficance & 3.633 & 3.952 & 2.502 & 1.471 & 3.109 & 1.940 & 8.009 \\
\hline $\mathrm{p}$ value & 0.016 & 0.011 & 0.064 & 0.227 & 0.030 & 0.095 & 0.000 \\
\hline boots. p & 0.017 & 0.005 & 0.054 & 0.233 & 0.071 & 0.049 & 0.004 \\
\hline
\end{tabular}

Source: Authors' calculations using survey data

Robust standard errors in parentheses. Bootstrapped p-values in brackets. The null hypothesis is that the point estimate is zero.

***: significant at the $1 \%$ level, **: significant at the $5 \%$ level, *: significant at the $10 \%$ level. 
Table 10: Marginal Effects at Sample Means on Urban Migrant Uptake of Insurance

\begin{tabular}{|c|c|c|c|c|c|c|c|c|c|}
\hline Dependent variable: & (1) & $(2)$ & \multicolumn{2}{|c|}{$\begin{array}{cc}(3) & (4) \\
\text { Insurance Uptake by Urban Migrant }\end{array}$} & \multicolumn{2}{|c|}{$(5)$} & \multicolumn{2}{|c|}{ (6) } & \\
\hline Pay to relative & 0.170 & 0.206 & 0.176 & 0.180 & & 0.186 & & 0.178 & \\
\hline p-value & 0.041 & 0.017 & 0.042 & 0.032 & & 0.032 & & 0.037 & \\
\hline bootstrapped p-value & 0.018 & 0.010 & 0.023 & 0.019 & & 0.024 & & 0.020 & \\
\hline Interacted with: & $\begin{array}{r}\text { Years in } \\
\text { Ouagadougou }\end{array}$ & $\begin{array}{l}\text { Frequency of shocks } \\
\text { reported by migrant }\end{array}$ & $\begin{array}{l}\text { Frequency of shocks } \\
\text { reported by hh }\end{array}$ & $\begin{array}{l}\text { Financial support } \\
\text { reported by hh }\end{array}$ & \multicolumn{2}{|c|}{$\begin{array}{l}\text { Financial support } \\
\text { reported by migrant }\end{array}$} & \multicolumn{2}{|c|}{$\begin{array}{r}\text { Any financial } \\
\text { support }\end{array}$} & \\
\hline & 0.009 & 0.059 & -0.024 & 0.110 & & 0.099 & & 0.152 & \\
\hline $\mathrm{p}$-value & 0.824 & 0.082 & 0.560 & 0.185 & & 0.219 & & 0.034 & \\
\hline bootstrapped p-value & 0.810 & 0.068 & 0.507 & 0.146 & & 0.183 & & 0.017 & \\
\hline & $(7)$ & (8) & (9) & (10) & $(11)$ & & $(12)$ & & (13) \\
\hline Dependent variable: & \multicolumn{4}{|c|}{ Insurance Uptake by Urban Migrant } & & & & & \\
\hline Pay to relative & 0.223 & 0.167 & 0.176 & 0.173 & 0.184 & & 0.182 & & 0.144 \\
\hline p-value & 0.012 & 0.044 & 0.036 & 0.043 & 0.028 & & 0.029 & & 0.091 \\
\hline bootstrapped p-value & 0.010 & 0.027 & 0.016 & 0.025 & 0.012 & & 0.017 & & 0.072 \\
\hline \multirow[t]{2}{*}{ Interacted with: } & $\begin{array}{l}\text { Coverable shock } \\
\text { reported by migrant }\end{array}$ & $\begin{array}{l}\text { Coverable shock } \\
\text { reported by hh }\end{array}$ & $\begin{array}{l}\text { Migrant willing } \\
\text { to pay CFA } 2000\end{array}$ & $\begin{array}{l}\text { Rural hh willing } \\
\text { to pay CFA } 2000\end{array}$ & $\begin{array}{l}\text { Reporting } \\
\text { accuracy }\end{array}$ & \multicolumn{2}{|c|}{$\begin{array}{l}\text { Marketed to } \\
\text { mult. migrants }\end{array}$} & $\begin{array}{l}\text { Purchas } \\
\text { oth. mi }\end{array}$ & $\begin{array}{l}\text { sed by } \\
\text { grant }\end{array}$ \\
\hline & 0.207 & 0.012 & 0.135 & 0.046 & 0.136 & & 0.138 & & -0.294 \\
\hline p-value & 0.018 & 0.903 & 0.177 & 0.678 & 0.076 & & 0.052 & & 0.020 \\
\hline bootstrapped p-value & 0.024 & 0.903 & 0.158 & 0.676 & 0.089 & & 0.048 & & 0.029 \\
\hline
\end{tabular}

Source: Authors' calculations using survey data

Robust standard errors in parentheses. Bootstrapped p-values in brackets. The null hypothesis is that the point estimate is zero. 
Table 11: Determinants of Take-Up of Rainfall Indexed Insurance by Urban Migrants, Adjusting for Attrition

\begin{tabular}{|c|c|c|c|c|c|c|c|}
\hline \multirow[b]{2}{*}{ Dependent variable: } & (1) & $(2)$ & $(3)$ & $(4)$ & $(5)$ & (6) & (7) \\
\hline & \multicolumn{7}{|c|}{ Insurance Uptake by Urban Migrant } \\
\hline \multicolumn{8}{|l|}{ Panel A } \\
\hline Pay to relative & $\begin{array}{r}0.247^{* * *} \\
(0.086) \\
{[0.002]}\end{array}$ & $\begin{array}{r}0.257^{* * *} \\
(0.088) \\
{[0.003]}\end{array}$ & $\begin{array}{r}0.232^{* * *} \\
(0.086) \\
{[0.004]}\end{array}$ & $\begin{array}{r}0.230^{* * *} \\
(0.084) \\
{[0.003]}\end{array}$ & $\begin{array}{r}0.236^{* * *} \\
(0.086) \\
{[0.005]}\end{array}$ & $\begin{array}{r}0.229^{* * *} \\
(0.085) \\
{[0.003]}\end{array}$ & $\begin{array}{r}0.280^{* * *} \\
(0.089) \\
{[0.003]}\end{array}$ \\
\hline \multicolumn{8}{|l|}{ Panel B } \\
\hline Pay to relative & $\begin{array}{r}0.197^{* *} \\
(0.085) \\
{[0.013]}\end{array}$ & $\begin{array}{c}0.222^{* *} \\
(0.085) \\
{[0.005]}\end{array}$ & $\begin{array}{c}0.185^{* *} \\
(0.085) \\
{[0.021]}\end{array}$ & $\begin{array}{c}0.185^{* *} \\
(0.084) \\
{[0.015]}\end{array}$ & $\begin{array}{c}0.202^{* *} \\
(0.085) \\
{[0.012]}\end{array}$ & $\begin{array}{r}0.187^{* *} \\
(0.084) \\
{[0.018]}\end{array}$ & $\begin{array}{r}0.235^{* * *} \\
(0.089) \\
{[0.004]}\end{array}$ \\
\hline \multicolumn{8}{|l|}{ Panel $C$} \\
\hline \multirow[t]{2}{*}{ Pay to relative } & $\begin{array}{c}0.170^{*} \\
(0.089) \\
{[0.048]}\end{array}$ & $\begin{array}{c}0.193^{* *} \\
(0.091) \\
{[0.028]}\end{array}$ & $\begin{array}{c}0.156^{*} \\
(0.092) \\
{[0.0771]}\end{array}$ & $\begin{array}{r}0.150^{*} \\
(0.090) \\
{[0.0821]}\end{array}$ & $\begin{array}{c}0.165^{*} \\
(0.091) \\
{[0.0601]}\end{array}$ & $\begin{array}{r}0.146 \\
(0.089) \\
{[0.0931]}\end{array}$ & $\begin{array}{c}0.202^{* *} \\
(0.094) \\
{[0.022]}\end{array}$ \\
\hline & (8) & (9) & (10) & (11) & $(12)$ & (13) & \\
\hline Dependent variable: & \multicolumn{6}{|c|}{ Insurance Uptake by Urban Migrant } & \\
\hline \multicolumn{8}{|l|}{ Panel $A$} \\
\hline Pay to relative & $\begin{array}{r}0.231 * * * \\
(0.086) \\
{[0.002]}\end{array}$ & $\begin{array}{r}0.233^{* * *} \\
(0.086) \\
{[0.005]}\end{array}$ & $\begin{array}{r}0.232^{* * *} \\
(0.086) \\
{[0.004]}\end{array}$ & $\begin{array}{r}0.238^{* * *} \\
(0.084) \\
{[0.001]}\end{array}$ & $\begin{array}{r}0.243^{* * *} \\
(0.083) \\
{[0.002]}\end{array}$ & $\begin{array}{c}0.202^{* *} \\
(0.086) \\
{[0.018]}\end{array}$ & \\
\hline \multicolumn{8}{|l|}{ Panel $B$} \\
\hline Pay to relative & $\begin{array}{r}0.191^{* *} \\
(0.085) \\
{[0.015]}\end{array}$ & $\begin{array}{r}0.187^{* *} \\
(0.085) \\
{[0.015]}\end{array}$ & $\begin{array}{r}0.188^{* *} \\
(0.085) \\
{[0.018]}\end{array}$ & $\begin{array}{c}0.202 * * \\
(0.082) \\
{[0.011]}\end{array}$ & $\begin{array}{c}0.169^{*} \\
(0.090) \\
{[0.050]}\end{array}$ & $\begin{array}{r}0.124 \\
(0.093) \\
{[0.165]}\end{array}$ & \\
\hline \multicolumn{8}{|l|}{ Panel $C$} \\
\hline Pay to relative & $\begin{array}{c}0.157^{*} \\
(0.093) \\
{[0.0771]}\end{array}$ & $\begin{array}{c}0.157^{*} \\
(0.090) \\
{[0.0731]}\end{array}$ & $\begin{array}{c}0.156^{*} \\
(0.092) \\
{[0.0771]}\end{array}$ & $\begin{array}{c}0.172^{* *} \\
(0.086) \\
{[0.039]}\end{array}$ & $\begin{array}{c}0.156^{*} \\
(0.092) \\
{[0.077]}\end{array}$ & $\begin{array}{c}0.172^{* *} \\
(0.086) \\
{[0.039]}\end{array}$ & \\
\hline
\end{tabular}

Robust standard errors in parentheses. Bootstrapped p-values in brackets. The null hypothesis is that the point estimate is zero.

***: significant at the $1 \%$ level, ${ }^{* *}$ : significant at the $5 \%$ level, $*$ : significant at the $10 \%$ level. 
Appendix 
Figure A1: Census Villages

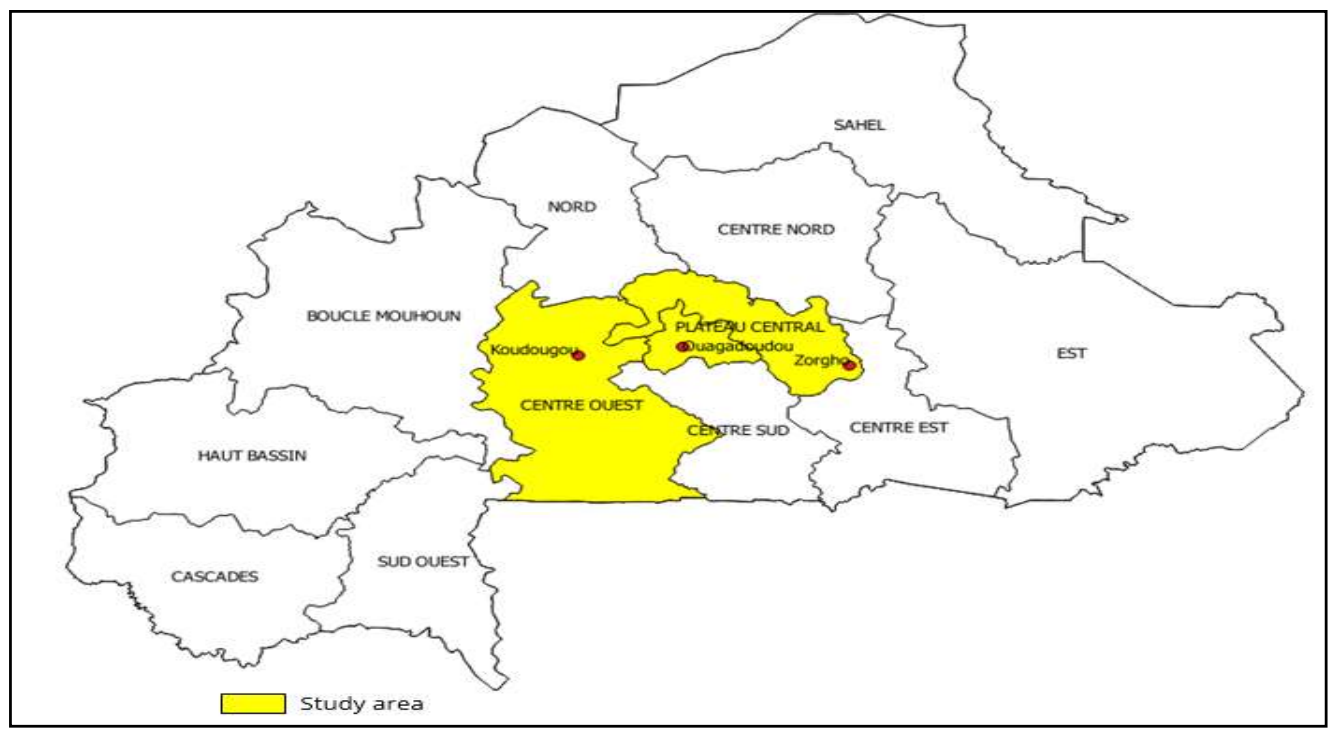


Table A1: List of survey villages and neighborhoods, and numbers of census households

\begin{tabular}{lrr}
\hline Village & Neighborhoods & Number of \\
\hline Name & Households \\
Bayandi-Nabyiri & Bayandi-Nabyiri & 50 \\
Bayandi-Tanguen & Bayandi & 61 \\
Badnogo & Badnogo & 33 \\
Bouloum-Nabyiri & Relwende & 50 \\
Dakongo & Rassembin & 49 \\
Kabinou & Tensogyiri & 53 \\
Kamsi & Katingyiiri & 53 \\
Kolonkand & Rana & 54 \\
Nobtenga & Nobtenga & 47 \\
Ouavouss & Natenga & 51 \\
Ralo & Gouroungo & 31 \\
& Nabyiri & 22 \\
Ramatoulaye & Farangin & 45 \\
Ramonkodogo & Ramonkodogo-Centre & 29 \\
Silmiougou & Baongnonre & 25 \\
Tanguen & Kombi & 43 \\
Tansga & Tanguen & 43 \\
Wemyaoguen & Tansga & 51 \\
Yagoam & Nabtenga & 49 \\
Yargo-Yarce & Yagoam & 40 \\
Zantonr & Kouglin & 51 \\
Source: Authors' calculations using survey data. & 48 \\
\hline
\end{tabular}


Table A2: Differences between migrants who were successfully tracked and those not found based on rural respondents' reports

\begin{tabular}{|c|c|c|c|}
\hline & Urban migrant & Urban migrant & Difference \\
\hline Rural respondent reporting $t$ & $\begin{array}{c}\text { found } \\
\text { at urban migrant: }\end{array}$ & not found & \\
\hline has invesment in village & 0.149 & 0.075 & $\begin{array}{l}0.074^{*} \\
{[0.039]}\end{array}$ \\
\hline provided financial support & 0.636 & 0.456 & $\begin{array}{r}0.181^{* * *} \\
{[0.069]}\end{array}$ \\
\hline is biological child & 0.504 & 0.605 & $\begin{array}{r}-0.101^{*} \\
{[0.056]}\end{array}$ \\
\hline is sibling & 0.347 & 0.211 & $\begin{array}{r}0.136^{* * *} \\
{[0.044]}\end{array}$ \\
\hline is male & 0.777 & 0.599 & $\begin{array}{r}0.178 * * * \\
{[0.068]}\end{array}$ \\
\hline migrated for work & 0.686 & 0.626 & $\begin{array}{r}0.06 \\
{[0.050]}\end{array}$ \\
\hline is formal wage worker & 0.149 & 0.068 & $\begin{array}{l}0.081^{*} \\
{[0.044]}\end{array}$ \\
\hline works in informal sector & 0.207 & 0.19 & $\begin{array}{r}0.016 \\
{[0.054]}\end{array}$ \\
\hline is a trader & 0.248 & 0.293 & $\begin{array}{l}-0.045 \\
{[0.064]}\end{array}$ \\
\hline attended primary education & 0.256 & 0.184 & $\begin{array}{r}0.073 \\
{[0.058]}\end{array}$ \\
\hline attended secondary education & 0.281 & 0.231 & $\begin{array}{r}0.05 \\
{[0.044]}\end{array}$ \\
\hline attended university & 0.091 & 0.041 & $\begin{array}{r}0.05 \\
{[0.031]}\end{array}$ \\
\hline
\end{tabular}

Source: Authors' calculations using survey data

Robust standard errors in parentheses.

***: significant at the $1 \%$ level, ${ }^{* *}$ : significant at the $5 \%$ level, *: significant at the $10 \%$ level. 
Table A3: Determinants of the probability that an urban migrant is tracked successfully based on rural survey

\begin{tabular}{|c|c|c|}
\hline & (1) & $(2)$ \\
\hline Dependent variable: & \multicolumn{2}{|c|}{ urban migrant tracked successfully } \\
\hline \multicolumn{3}{|c|}{ Rural respondent reporting that urban migrant: } \\
\hline \multirow[t]{2}{*}{ has invesment in village } & 0.386 & 0.322 \\
\hline & $(0.242)$ & $(0.270)$ \\
\hline \multirow[t]{2}{*}{ is biological child } & 0.075 & 0.094 \\
\hline & $(0.215)$ & $(0.221)$ \\
\hline \multirow[t]{2}{*}{ is sibling } & $0.444^{* *}$ & $0.397^{*}$ \\
\hline & $(0.227)$ & $(0.236)$ \\
\hline \multirow[t]{2}{*}{ is male } & $0.455^{*}$ & $0.590^{*}$ \\
\hline & $(0.262)$ & $(0.301)$ \\
\hline \multirow[t]{2}{*}{ migrated for work } & -0.210 & -0.248 \\
\hline & $(0.182)$ & $(0.217)$ \\
\hline \multirow[t]{2}{*}{ is formal wage worker } & 0.349 & 0.283 \\
\hline & $(0.241)$ & $(0.255)$ \\
\hline \multirow[t]{2}{*}{ works in informal sector } & 0.196 & 0.154 \\
\hline & $(0.240)$ & $(0.290)$ \\
\hline \multirow[t]{2}{*}{ is a trader } & 0.006 & 0.015 \\
\hline & $(0.235)$ & $(0.298)$ \\
\hline \multirow[t]{2}{*}{ attended primary education } & $0.443^{*}$ & 0.405 \\
\hline & $(0.245)$ & $(0.249)$ \\
\hline \multirow[t]{2}{*}{ attended secondary education } & $0.321^{*}$ & 0.338 \\
\hline & $(0.185)$ & $(0.222)$ \\
\hline \multirow[t]{2}{*}{ attended university } & 0.584 & 0.606 \\
\hline & $(0.430)$ & $(0.471)$ \\
\hline \multirow[t]{2}{*}{ Constant } & $-0.798^{* * *}$ & -0.345 \\
\hline & $(0.233)$ & $(0.314)$ \\
\hline vill. dummies & no & yes \\
\hline Chi2-Stat. joint signficance & 71.07 & 51.79 \\
\hline $\mathrm{p}$ value & 0.00 & 0.00 \\
\hline
\end{tabular}


Table A4: Determinants of take-up of rainfall indexed insurance by urban migrants, controlling for migrant characteristics as reported by rural respondents

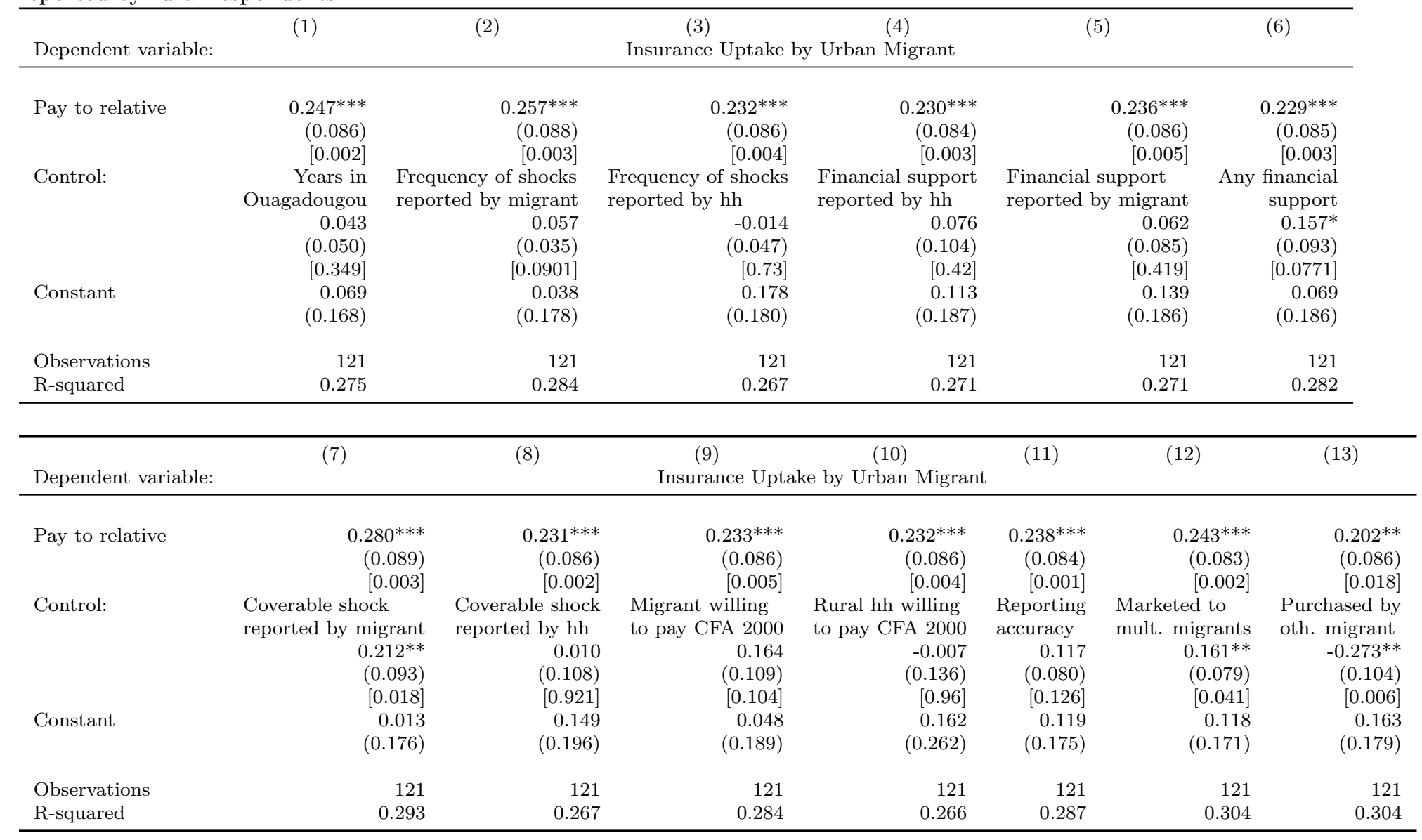

Source: Authors' calculations using survey data

Robust standard errors in parentheses. Bootstrapped p-values in brackets. The null hypothesis is that the point estimate is zero.

***: significant at the $1 \%$ level, **: significant at the $5 \%$ level, *: significant at the $10 \%$ level. 
Table A5: Determinants of take-up of rainfall indexed insurance by urban migrants: inverse-probability weighted estimations

\begin{tabular}{|c|c|c|c|c|c|c|}
\hline Dependent Variable: & (1) & (2) & $\begin{array}{c}\text { (3) } \\
\text { Insurance Uptake b }\end{array}$ & $\begin{array}{c}(4) \\
\text { Urban Migrant }\end{array}$ & $(5)$ & $(6)$ \\
\hline \multirow[t]{3}{*}{ Pay to relative } & $0.197^{* *}$ & $0.222^{* *}$ & $0.185^{* *}$ & $0.185^{* *}$ & $0.202^{* *}$ & $0.187^{* *}$ \\
\hline & $(0.085)$ & $(0.085)$ & $(0.085)$ & $(0.084)$ & $(0.085)$ & $(0.084)$ \\
\hline & {$[0.013]$} & {$[0.005]$} & {$[0.021]$} & {$[0.015]$} & {$[0.012]$} & {$[0.018]$} \\
\hline \multirow[t]{5}{*}{ Control Variable: } & Years in & Frequency of shocks & Frequency of shocks & Financial support & Financial support & Any financial \\
\hline & Ouagadougou & reported by migrant & reported by hh & reported by hh & reported by migrant & support \\
\hline & 0.062 & 0.057 & -0.027 & 0.112 & 0.115 & $0.163^{* *}$ \\
\hline & $(0.047)$ & $(0.035)$ & $(0.041)$ & $(0.081)$ & $(0.081)$ & $(0.075)$ \\
\hline & {$[0.176]$} & {$[0.089]$} & {$[0.48]$} & {$[0.11]$} & {$[0.129]$} & {$[0.022]$} \\
\hline \multirow[t]{2}{*}{ Constant } & 0.055 & 0.062 & 0.225 & 0.089 & 0.123 & 0.049 \\
\hline & $(0.123)$ & $(0.148)$ & $(0.152)$ & $(0.145)$ & $(0.146)$ & $(0.138)$ \\
\hline Observations & 121 & 121 & 121 & 121 & 121 & 121 \\
\hline R-squared & 0.224 & 0.225 & 0.207 & 0.218 & 0.220 & 0.229 \\
\hline
\end{tabular}

E

\begin{tabular}{|c|c|c|c|c|c|}
\hline \multirow{2}{*}{ Dependent Variable: } & \multirow[t]{2}{*}{ (7) } & \multirow{2}{*}{\multicolumn{3}{|c|}{$\begin{array}{l}(8) \\
\text { Insurance Uptake by Urban Migrant }\end{array}$}} & \multirow[t]{2}{*}{ (11) } \\
\hline & & & & & \\
\hline \multirow[t]{3}{*}{ Pay to relative } & $0.235^{* * *}$ & $0.191^{* *}$ & $0.187^{* *}$ & $0.188^{* *}$ & $0.202^{* *}$ \\
\hline & $(0.089)$ & $(0.085)$ & $(0.085)$ & $(0.085)$ & $(0.082)$ \\
\hline & {$[0.004]$} & {$[0.015]$} & {$[0.015]$} & {$[0.018]$} & {$[0.011]$} \\
\hline \multirow[t]{5}{*}{ Control Variable: } & Coverable shock & Coverable shock & Migrant willing & Rural hh willing & Reporting \\
\hline & reported by migrant & reported by hh & to pay CFA 2000 & to pay CFA 2000 & accuracy \\
\hline & $0.212^{* *}$ & -0.023 & 0.149 & 0.032 & $0.151^{* *}$ \\
\hline & $(0.091)$ & $(0.109)$ & $(0.100)$ & $(0.108)$ & $(0.074)$ \\
\hline & {$[0.012]$} & {$[0.822]$} & {$[0.127]$} & {$[0.745]$} & [0.049] \\
\hline \multirow[t]{2}{*}{ Constant } & 0.015 & 0.192 & 0.096 & 0.146 & 0.089 \\
\hline & $(0.148)$ & $(0.157)$ & $(0.141)$ & $(0.191)$ & $(0.137)$ \\
\hline Observations & 121 & 121 & 121 & 121 & 121 \\
\hline R-squared & 0.231 & 0.205 & 0.220 & 0.205 & 0.247 \\
\hline
\end{tabular}

Robust standard errors in parentheses. Bootstrapped p-values in brackets. The null hypothesis is that the point estimate is zero

***: significant at the $1 \%$ level, **: significant at the $5 \%$ level, *: significant at the $10 \%$ level. 
Table A6: Determinants of take-up of rainfall indexed insurance by urban migrants: inverse-probability weighted estimations with village dummies included in the probability regression

\begin{tabular}{|c|c|c|c|c|c|c|}
\hline Dependent Variable: & (1) & (2) & $\begin{array}{c}(3) \\
\text { Insurance Uptake b }\end{array}$ & $\begin{array}{c}(4) \\
\text { Urban Migrant }\end{array}$ & (5) & (6) \\
\hline \multirow[t]{2}{*}{ Pay to relative } & $0.170^{*}$ & $0.193^{* *}$ & $0.156^{*}$ & $0.150^{*}$ & $0.165^{*}$ & 0.146 \\
\hline & {$[0.048]$} & {$[0.028]$} & {$[0.077]$} & {$[0.082]$} & {$[0.060]$} & [0.093] \\
\hline \multirow[t]{2}{*}{ Control: } & Years in & Frequency of shocks & Frequency of shocks & Financial support & Financial support & Any financial \\
\hline & 0.077 & $0.066^{*}$ & -0.007 & $0.142^{*}$ & 0.130 & $\begin{array}{l}\text { support } \\
0.197^{* *}\end{array}$ \\
\hline Constant & $\begin{array}{r}0.087 \\
(0.134)\end{array}$ & $\begin{array}{r}0.116 \\
(0.163)\end{array}$ & $\begin{array}{r}0.270 \\
(0.165)\end{array}$ & $\begin{array}{r}0.151 \\
(0.158)\end{array}$ & $\begin{array}{r}0.199 \\
(0.163)\end{array}$ & $\begin{array}{r}0.107 \\
(0.152)\end{array}$ \\
\hline Observations & 121 & 121 & 121 & 121 & 121 & 121 \\
\hline R-squared & 0.225 & 0.220 & 0.194 & 0.215 & 0.213 & 0.228 \\
\hline
\end{tabular}

$\mapsto$

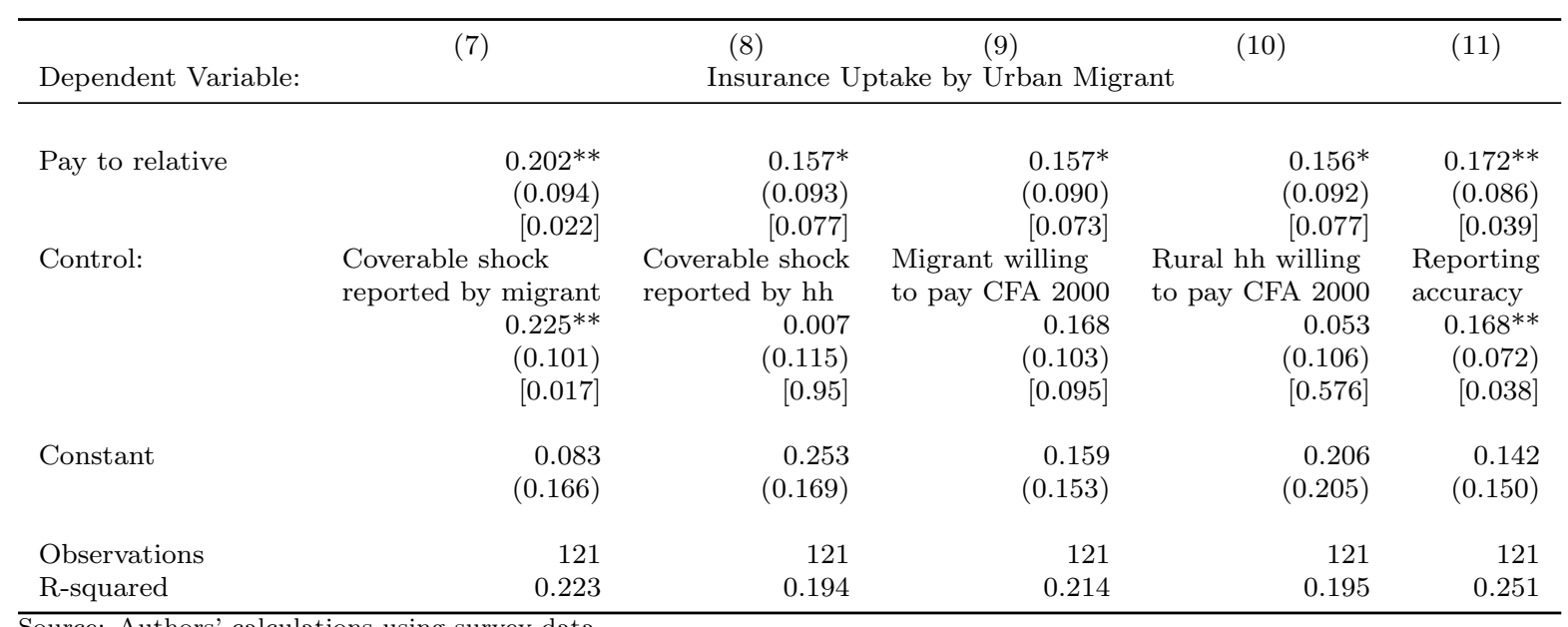

Source: Authors' calculations using survey data

Robust standard errors in parentheses. Bootstrapped p-values in brackets. The null hypothesis is that the point estimate is zero.

***: significant at the $1 \%$ level, **: significant at the $5 \%$ level, *: significant at the $10 \%$ level. 